\title{
CH in stellar atmospheres: an extensive linelist ${ }^{\star}$
}

\author{
T. Masseron ${ }^{1}$, B. Plez ${ }^{2}$, S. Van Eck ${ }^{1}$, R. Colin ${ }^{3}$, I. Daoutidis ${ }^{1}$, M. Godefroid ${ }^{3}$, P.-F. Coheur ${ }^{3}$, P. Bernath ${ }^{4}$, \\ A. Jorissen ${ }^{1}$, and N. Christlieb ${ }^{5}$ \\ 1 Institut d'Astronomie et d'Astrophysique, Université Libre de Bruxelles (ULB), CP 226, Boulevard du Triomphe, 1050 Bruxelles, \\ Belgium \\ e-mail: tpm40@ast.cam.ac.uk \\ 2 Laboratoire Univers et Particules de Montpellier, Université Montpellier 2, CNRS, 34095 Montpellier, France \\ 3 Service de Chimie quantique et Photophysique, Université Libre de Bruxelles, CP160/09, avenue F.D. Roosevelt 50, 1050 Bruxelles, \\ Belgium \\ 4 Department of Chemistry \& Biochemistry, Old Dominion University, Norfolk, VA, USA \\ 5 University of Heidelberg, Zentrum für Astronomie, Landessternwarte, Königstuhl 12, 69117 Heidelberg, Germany
}

Received 7 April 2014 / Accepted 2 June 2014

\begin{abstract}
The advent of high-resolution spectrographs and detailed stellar atmosphere modelling has strengthened the need for accurate molecular data. Carbon-enhanced metal-poor (CEMP) stars spectra are interesting objects with which to study transitions from the $\mathrm{CH}$ molecule. We combine programs for spectral analysis of molecules and stellar-radiative transfer codes to build an extensive $\mathrm{CH}$ linelist, including predissociation broadening as well as newly identified levels. We show examples of strong predissociation $\mathrm{CH}$ lines in CEMP stars, and we stress the important role played by the $\mathrm{CH}$ features in the Bond-Neff feature depressing the spectra of barium stars by as much as $0.2 \mathrm{mag}$ in the $\lambda=3000-5500 \AA$ range. Because of the extreme thermodynamic conditions prevailing in stellar atmospheres (compared to the laboratory), molecular transitions with high energy levels can be observed. Stellar spectra can thus be used to constrain and improve molecular data.
\end{abstract}

Key words. molecular data - techniques: spectroscopic - stars: carbon

\section{Introduction}

The computation of stellar atmosphere models requires, among various other ingredients, the knowledge of radiative transition rates for a large number of atomic and molecular species (Gustafsson et al. 2008). Extensive linelists, as complete as possible, with accurate oscillator strength values are needed for the calculation of opacities that affect the thermal structure of the atmosphere. The computation of detailed emergent spectra also requires accurate line positions (Plez 2008). The advent of high-resolution spectrographs on $8 \mathrm{~m}$-class telescopes (e.g. VLT/UVES, Keck/HIRES, VLT/CRIRES, SUBARU/HRS) allows a very detailed study of spectra of many astronomical objects. The discussion of possible abundance pattern differences between stars with and without planets lies now at a level of the order of 0.01 dex (Gustafsson et al. 2010; Asplund 2005). The conclusions therefore heavily depend on the quality of the whole chain of data acquisition and analysis, not the least of which are the physical data. This kind of study requires a line position accuracy of the order of a few hundredths of $\AA$ or $\mathrm{cm}^{-1}$ in the optical domain, and oscillator strengths with an accuracy better than $5 \%$.

Great efforts have been devoted to improving atomic and molecular line data, e.g. VALD (Kupka et al. 1999) and DREAM (Biémont et al. 1999) for atoms, and Bernath (2009) and EXOMOL (Tennyson \& Yurchenko 2012) for molecules. In particular, many transitions have been analysed in the laboratory,

* Full Table 14 is only available at the CDS via anonymous ftp to cdsarc.u-strasbg.fr (130.79.128.5) or via http://cdsarc.u-strasbg.fr/viz-bin/qcat?]/A+A/571/A47 leading to a large number of accurate line positions, and molecular constants. However, line strength information is often missing, and lines involving highly excited states, not visible in the laboratory but important in warm astrophysical environments like stellar atmospheres, are lacking. We are therefore aiming at constructing molecular linelists for astrophysical use. The present paper targets $\mathrm{CH}$.

The $\mathrm{CH}$ molecule is one of the most studied free radicals because it forms in various physical and astrophysical environments. This molecule was first detected by Heurlinger \& Hulthen (1919) and then studied by many scientists (see references in Kalemos et al. 1999). This molecule has many valence and Rydberg states as reviewed by Vázquez et al. (2007), but only the lower energy states are of interest for stellar astrophysics. Our aim in this paper is to improve the situation for the ro-vibrational $\mathrm{X}^{2} \Pi-\mathrm{X}^{2} \Pi$ and the $\mathrm{A}^{2} \Delta-\mathrm{X}^{2} \Pi, \mathrm{B}^{2} \Sigma^{-}-\mathrm{X}^{2} \Pi$, and $\mathrm{C}^{2} \Sigma^{+}-\mathrm{X}^{2} \Pi$ electronic transitions of $\mathrm{CH}$ (for both ${ }^{12} \mathrm{CH}$ and ${ }^{13} \mathrm{CH}$ isotopologues). Bound-bound transitions for $\mathrm{CH}$ appear in the near UV spectra of almost all F, G, K stars, whatever their carbon enrichment is. The $G$ band at $4300 \AA$ is particularly prominent, and is used, for example as a criterion for stellar classification ( $\mathrm{CH}$ stars), and as a proxy for magnetic flux concentrations in the solar photosphere (Shelyag et al. 2004). As another example the ${ }^{12} \mathrm{C} /{ }^{13} \mathrm{C}$ isotopic ratio can be derived from the $\mathrm{CH}$ molecular lines in the near $\mathrm{UV}$, and are often the only available carbon abundance indicator in very metal-poor stars. In addition, a good knowledge of the $\mathrm{CH}$ lines in the blue-UV part of the spectrum is also a prerequisite for determining the abundance of heavier metals (e.g. $\mathrm{Bi}, \mathrm{Pb}$, and $\mathrm{U}$ ) in stellar environments, as these lines often blend those of the atomic species. To date, three linelists exist for $\mathrm{CH}$. The first 
two have been available for a long time: one from R. Kurucz ${ }^{1}$, for which there is little information on how the linelist was computed, and the SCAN-CH of Jorgensen et al. (1996), which also contains the ro-vibrational $\mathrm{X}-\mathrm{X}$ transition. More recently, we compiled a third linelist, published as a poster at the "14th Cool Stars, Stellar Systems, and the Sun" conference in Pasadena, in 2006, and distributed since then by Plez. This list was assembled after our discovery that unidentified strong and broad lines in the near-UV spectrum of carbon-enhanced metal-poor (CEMP) stars were due to predissociation lines of $\mathrm{CH}$ (see the Appendix). The line positions and $g f$ values come from the LIFBASE program (Luque \& Crosley 1999); excitation energies from the SCAN linelist, and isotopic shifts were recomputed by our team.

It is this last linelist that is presented and discussed here, but we have largely updated it by (i) the computation of a uniform set of molecular constants from laboratory data supplemented by our measurement of high excitation lines in stellar spectra; (ii) the inclusion of both the observed and calculated line positions; (iii) the inclusion of radiative damping parameters accounting for pre-dissociation; and (iv) the inclusion of the ro-vibrational $\mathrm{X}-\mathrm{X}$ transition. The paper is structured as follows: first, we explain the method used to derive the linelist (Sect. 2), then we describe the data we have used for ${ }^{12} \mathrm{CH}$ and ${ }^{13} \mathrm{CH}$ (Sect. 3), and finally we summarize the content of the list (Sect. 4); we illustrate its improvements for stellar spectra in the Appendix.

\section{Method}

At least two parameters are required to assemble a molecular linelist: line positions and absolute line intensities. Other parameters may be added, e.g. collisional broadening parameters or Landé factors. Ab initio calculations can be attempted, but the use of observed line positions and intensities is more reliable. We therefore collected extensive laboratory data for ${ }^{12} \mathrm{CH}$ and ${ }^{13} \mathrm{CH}$, which we supplemented with line positions extracted from stellar spectra.

We followed the method outlined in Li et al. (2012). First, we used the PGopher ${ }^{2}$ software to determine molecular constants from line positions. For the specific case of $\mathrm{CH}$, these molecular constants include vibrational, rotational, and spinrotational constants for all electronic states as well as spin-orbit and $\Lambda$-doubling constants for the $\mathrm{X}^{2} \Pi$ and $\mathrm{A}^{2} \Delta$ states. The line positions used as input to PGopher were weighted according to the quoted accuracy of the various sources.

The version of PGopher we use is able to generate linelists and also provides Hönl-London factors for doublet states. The computation of Einstein coefficients requires, however, the knowledge of transition moments. Hence, in a second step, from the vibration-dependent constants provided by PGopher, we derived the Dunham constants and used them in the $\mathrm{RKR}^{3}$ code to calculate the potential $V_{J}(r)$. These potentials were injected into the LEVEL $^{3}$ program to compute the transition moment matrix elements, $\left\langle v^{\prime} J^{\prime}|\operatorname{Re}(r)| v^{\prime \prime} J^{\prime \prime}\right\rangle$, where $\operatorname{Re}(r)$ is the transition moment as a function of the internuclear distance $r$, and $\left|v^{\prime} J^{\prime}\right\rangle$

\footnotetext{
1 Bob Kurucz' CD-ROM 15 or http://kurucz.harvard.edu/ linelists.html

2 PGOPHER version 8.0, a Program for Simulating Rotational Structure, C.M. Western, University of Bristol, http://pgopher. chem.bris.ac.uk/.

3 RKR (v2.0) and LEVEL (v8.0) are programs developed by Robert Leroy, University of Waterloo Chemical Physics Research Reports CP663 (2007) and CP-657R (2004), http://leroy.uwaterloo.ca/ programs/.
}

and $\left|v^{\prime \prime} J^{\prime \prime}\right\rangle$ are, respectively, the upper and the lower state vibrational wavefunctions. The matrix elements of the $\mathrm{R}(0)$ levels were then used as input to PGopher. However, in contrast to $\mathrm{Li}$ et al. (2012), we attempt to consider the rotational dependence of the transition moment matrix elements because we observed transitions involving highly excited rotation levels in order to consider the rotational effect on oscillator strengths. For example, the Einstein coefficient is decreased by $\sim 40 \%$ between the lowest and the highest observed rotational $\mathrm{A}-\mathrm{X}$ transition. We simultaneously attempt to correct for the Herman-Wallis effect. In order to approximate the rotational dependence of the transition moment and the Herman-Wallis correction, we approximated the moment matrix elements provided by LEVEL by fitting a polynomial function such that

$\left|\left\langle v^{\prime} J^{\prime}|\operatorname{Re}(r)| v^{\prime \prime} J^{\prime \prime}\right\rangle\right|=\sum_{i=1}^{n} a_{i}\left(v^{\prime}, v^{\prime \prime}, J^{\prime}\right) J^{\prime \prime i}$,

where the polynomial order $n$ is determined by requiring the rms of the fit to be less than $1 \%$. Because the Einstein coefficient is proportional to the square of the transition matrix elements, we then correct the Einstein coefficients provided by the PGopher program by the square of the polynomial value for each transition. We note that it is not obvious that this polynomial fit of singlet-singlet transitions as delivered by LEVEL can be applied to doublet transitions. To test our approach, we therefore synthesize the solar spectrum with and without the polynomial correction. As demonstrated by Fig. 1, the synthetic spectrum of the Sun is improved greatly on the line intensity when corrections are applied.

In a third step, once a first $\mathrm{CH}$ linelist had been generated with PGopher, we generated a number of synthetic stellar spectra using Turbospectrum ${ }^{4}$, and appropriate MARCS stellar model atmospheres (Gustafsson et al. 2008). In addition to $\mathrm{CH}$, we included other atomic lines from VALD (Kupka et al. 1999; Hill et al. 2002; Masseron 2006), as well as molecular linelists of $\mathrm{CN}$ and $\mathrm{C}_{2}$ (Plez, priv. comm.) and $\mathrm{MgH}$ from the Kurucz linelists. These spectra were compared with carefully selected observed stellar spectra (see Sect. 3.3) in an attempt to identify $\mathrm{CH}$ lines as yet unobserved in the laboratory. Thanks to the specific thermodynamic conditions present in cool carbon-star atmospheres, new transitions could indeed be observed and assigned. Although the resolution of spectrographs mounted at telescopes (typically $\lambda / \Delta \lambda=60000$, or $\approx 0.4 \mathrm{~cm}^{-1}$ in our spectral range) does not reach that of laboratory spectrometers $\left(\approx 10^{-2} \mathrm{~cm}^{-1}\right)$, the inclusion of some high rotational transitions only observed in stellar spectra allows us to improve the determination of the molecular constants in PGopher, with the appropriate weight for each line set by the measurement accuracy. We iterated the process of identification in stellar spectra, and recalculated the list until no new lines could be identified.

Finally, we computed the radiative lifetime of each level $\left(\tau_{v^{\prime} J^{\prime}}\right)$ according to the formula

$\tau_{v^{\prime} J^{\prime}}=\left(\sum_{v^{\prime \prime} J^{\prime \prime}} A_{v^{\prime} J^{\prime} v^{\prime \prime} J^{\prime \prime}}\right)^{-1}$,

where $A_{v^{\prime} J^{\prime} v^{\prime \prime} J^{\prime \prime}}$ is the Einstein coefficient of one transition. As $\mathrm{CH}$ is a molecule known to show predissociation (Herzberg \& Johns 1969), we also included the predissociation lifetimes, in order to allow for a better estimate of the line broadening parameter $\Gamma_{\text {rad }}=1 / \tau_{v^{\prime} J^{\prime}}+1 / \tau_{\text {predissoc }}$.

4 Turbospectrum, a LTE radiative transfer code for spectral synthesis in cool stellar atmospheres (see Alvarez \& Plez 1998; Plez 2012). 


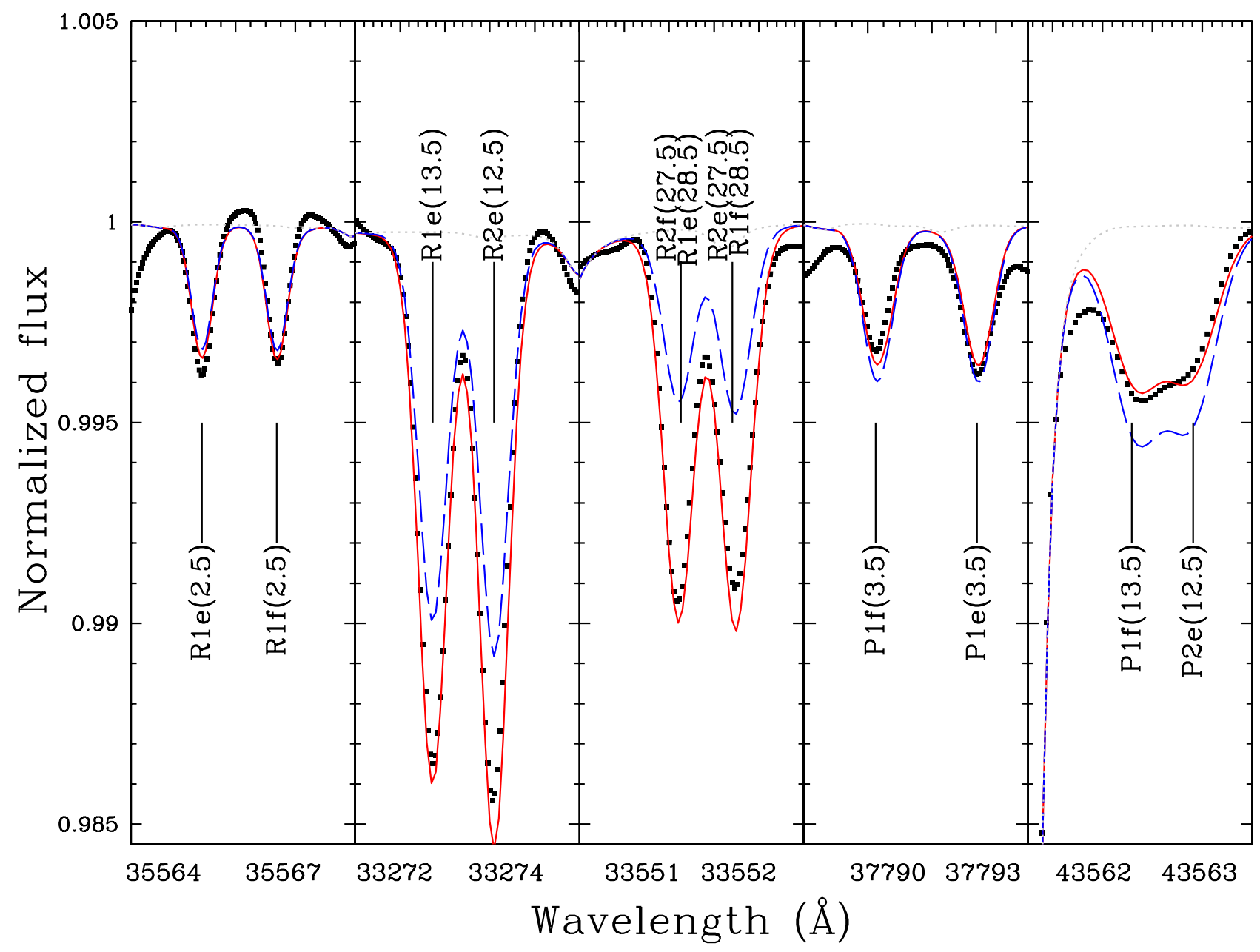

Fig. 1. Synthetic spectrum of the Sun near the 1-0 ro-vibrational band of CH compared to the observed solar spectrum (ACE; Bernath et al. 2005; dotted line). The red line includes the $J$-dependence correction (see text) while the blue does not. The first 3 panels from left to right show from the $\mathrm{R}$ branch, for which intensity increases with increasing $J$. The increasing relative strength between the synthesis with and without the $J$-dependence correction demonstrates the rotational dependence of the transition moment for $\mathrm{CH}$. The two right panels show lines from the $\mathrm{P}$ branch. The fact that the $J$-dependence correction is not the same as for R branches is due to the Herman-Wallis effect.

\section{Observed transitions}

\section{1. ${ }^{12} \mathrm{CH}$ laboratory data}

Laboratory data was collected from the literature. For the $\mathrm{X}^{2} \Pi$ fundamental state, we used the observations of Colin \& Bernath (2010) of the ro-vibrational transitions in the ACE (Atmospheric Chemical Experiment; Bernath et al. 2005) solar spectrum. The quality and resolution of this spectrum is close to laboratory standard $\left(0.02 \mathrm{~cm}^{-1}\right.$ in line position accuracy) and the 777 observed transitions allowed an accurate determination of the $\mathrm{X}^{2} \Pi$ state constants up to $v=5$. For the $\mathrm{A}^{2} \Delta-\mathrm{X}^{2} \Pi$ transition, we merged the laboratory measurements of Bernath et al. (1991) and Zachwieja (1995), with an average accuracy of $0.005 \mathrm{~cm}^{-1}$ over 665 and 432 observed transitions, respectively. The experimental data for the $\mathrm{B}^{2} \Sigma^{-}-\mathrm{X}^{2} \Pi$ transition was taken from Kepa (1996), Kumar et al. (1998), and Bernath et al. (1991), with respective accuracies (and number of lines) of $0.015 \mathrm{~cm}^{-1}$ (169), $0.01 \mathrm{~cm}^{-1}(73)$, and $0.005 \mathrm{~cm}^{-1}(126)$. When the same line was present in different studies, we favoured the value from the most accurate measurement. For the $C^{2} \Sigma^{+}-X^{2} \Pi$ transition, we used the experimental data from Bembenek et al. (1997; 56 lines), Ubachs et al. (1986; 35 lines), and Heimer (1932; 159 lines) for the $0-0$ transition with respective accuracies of $0.02 \mathrm{~cm}^{-1}$,
$0.003 \mathrm{~cm}^{-1}, 0.2 \mathrm{~cm}^{-1}$, and $\mathrm{Li}$ et al. (1999; 124 lines) for the $1-1$ transition with an accuracy of $0.05 \mathrm{~cm}^{-1}$, and Herzberg \& Johns (1969; 42 lines) for the 2-2 transition, with an accuracy of $0.2 \mathrm{~cm}^{-1}$. Some line assignments from these papers did not correspond to the identification we could make with PGopher. They were changed to the closest matching wavenumber when using the published constant of each author (see Table 1).

\section{2. ${ }^{13} \mathrm{CH}$}

We could not find any observations of the ${ }^{13} \mathrm{CH}$ ro-vibrational bands in the literature. For the $\mathrm{A}-\mathrm{X}, \mathrm{B}-\mathrm{X}$, and $\mathrm{C}-\mathrm{X}$ transitions, we use the observations of Zachwieja (1997; 601 lines), Para (1996; 177 lines), and Bembenek et al. (1997; 52 lines), with the respective quoted accuracies of $0.005 \mathrm{~cm}^{-1}, 0.015 \mathrm{~cm}^{-1}$, $0.02 \mathrm{~cm}^{-1}$. We reassigned some lines for ${ }^{12} \mathrm{CH}$ in order to match the PGopher identifications (see Table 2).

\subsection{Stellar observations and modelling}

One may wonder why predissociation lines of $\mathrm{CH}$, a molecule observed in basically all cool stars, were never detected before. They are definitely present (see Fig. 3), although never recognized, in stars as accurately known as the Sun, but such 
Table 1. Modified line assignments for the ${ }^{12} \mathrm{CH}$ transitions.

\begin{tabular}{|c|c|c|c|c|c|}
\hline \multicolumn{2}{|c|}{ Colin \& Bernath (2010) X-X } & \multicolumn{2}{|c|}{ Bernath et al. (1991) B-X } & \multicolumn{2}{|c|}{ Kepa (1996) B-X } \\
\hline $\begin{array}{l}\text { previous } \\
v^{\prime}-v^{\prime \prime} \mathrm{F}\left(J^{\prime \prime}\right)\end{array}$ & $\begin{array}{l}\text { new } \\
v^{\prime}-v^{\prime \prime} \mathrm{F}\left(J^{\prime \prime}\right)\end{array}$ & $\begin{array}{l}\text { previous } \\
v^{\prime}-v^{\prime \prime} \mathrm{F}\left(J^{\prime \prime}\right)\end{array}$ & $\begin{array}{l}\text { new } \\
v^{\prime}-v^{\prime \prime} \mathrm{F}\left(J^{\prime \prime}\right)\end{array}$ & $\begin{array}{l}\text { previous } \\
v^{\prime}-v^{\prime \prime} \mathrm{F}\left(J^{\prime \prime}\right)\end{array}$ & $\begin{array}{l}\text { new } \\
v^{\prime}-v^{\prime \prime} \mathrm{F}\left(J^{\prime \prime}\right)\end{array}$ \\
\hline $1-0$ P2ee(1.5) & $1-0$ P12ee(1.5) & $1-1 \mathrm{Q} 12 \mathrm{fe}(0.5)$ & $1-1 \mathrm{Q} 1 \mathrm{fe}(0.5)$ & $0-1$ P2ee(0.5) & $0-1 \mathrm{Q} 1 \mathrm{fe}(0.5)$ \\
\hline $1-0$ P2ff(1.5) & $1-0 \mathrm{P} 12 \mathrm{ff}(1.5)$ & $1-1 \mathrm{Q} 2 \mathrm{ef}(0.5)$ & $1-1 \mathrm{Q} 21 \mathrm{ef}(0.5)$ & $0-1 \mathrm{Q} 2 \mathrm{ef}(0.5)$ & $0-1 \mathrm{Q} 21 \mathrm{ef}(0.5)$ \\
\hline $2-1 \mathrm{P} 2 \mathrm{ee}(1.5)$ & $1-0$ P12ee(1.5) & $1-1 \mathrm{R} 1 \mathrm{ee}(0.5)$ & $1-1 \mathrm{R} 21 \mathrm{ee}(0.5)$ & $1-1 \mathrm{P} 2 \mathrm{ee}(0.5)$ & $1-1 \mathrm{Q} 1 \mathrm{fe}(0.5)$ \\
\hline 2-1 P2ff(1.5) & $1-0$ P12ff(1.5) & & & 1-1 Q2ef(0.5) & $1-1 \mathrm{Q} 21 \mathrm{ef}(0.5)$ \\
\hline $2-1 \mathrm{Q} 2 \mathrm{ef}(0.5)$ & $1-0$ Q1fe $(0.5)$ & & & & \\
\hline $2-1 \mathrm{Q} 2 \mathrm{fe}(0.5)$ & $1-0$ Q1ef $(0.5)$ & & & & \\
\hline $2-1 \mathrm{R} 2 \mathrm{ee}(0.5)$ & $1-0 \mathrm{R} 21 \mathrm{ee}(0.5)$ & & & & \\
\hline $2-1 \mathrm{R} 2 \mathrm{ff}(0.5)$ & $1-0 \mathrm{R} 21 \mathrm{ff}(0.5)$ & & & & \\
\hline 4-3 P2ee(1.5) & $1-0$ P12ee(1.5) & & & & \\
\hline 4-3 R2ff(0.5) & $1-0 \mathrm{R} 21 \mathrm{ff}(0.5)$ & & & & \\
\hline \multicolumn{2}{|c|}{ Zachwieja (1995) A-X } & \multicolumn{2}{|c|}{ Ubachs et al. (1986) C-X } & \multicolumn{2}{|c|}{ Bembenek et al. (1997) C-X } \\
\hline $\begin{array}{l}\text { previous } \\
v^{\prime}-v^{\prime \prime} \mathrm{F}\left(J^{\prime \prime}\right)\end{array}$ & $\begin{array}{l}\text { new } \\
v^{\prime}-v^{\prime \prime} \mathrm{F}\left(J^{\prime \prime}\right)\end{array}$ & $\begin{array}{l}\text { previous } \\
v^{\prime}-v^{\prime \prime} \mathrm{F}\left(J^{\prime \prime}\right)\end{array}$ & $\begin{array}{l}\text { new } \\
v^{\prime}-v^{\prime \prime} \mathrm{F}\left(J^{\prime \prime}\right)\end{array}$ & $\begin{array}{l}\text { previous } \\
v^{\prime}-v^{\prime \prime} \mathrm{F}\left(J^{\prime \prime}\right)\end{array}$ & $\begin{array}{l}\text { new } \\
v^{\prime}-v^{\prime \prime} \mathrm{F}\left(J^{\prime \prime}\right)\end{array}$ \\
\hline $1-1 \mathrm{R} 2 \mathrm{ff}(0.5)$ & $1-1 \mathrm{R} 21 \mathrm{ff}(0.5)$ & $0-0$ Q1ef(0.5) & $0-0$ Q12ef(0.5) & $0-0$ R21ff $(0.5)$ & NA \\
\hline $1-1 \mathrm{R} 2 \mathrm{ee}(0.5)$ & $1-1 \mathrm{R} 21 \mathrm{ee}(0.5)$ & $0-0$ Q21fe $(0.5)$ & $0-0 \mathrm{Q} 2 \mathrm{fe}(0.5)$ & & \\
\hline $2-2 \mathrm{R} 2 \mathrm{ff}(0.5)$ & 2-2 R21ff(0.5) & $0-0$ R1ee(0.5) & $0-0$ R12ee $(0.5)$ & & \\
\hline 2-2 R2ee(0.5) & 2-2 R21ee(0.5) & & & & \\
\hline $3-3 \mathrm{R} 2 \mathrm{ff}(0.5)$ & 3-3 R21ff(0.5) & & & & \\
\hline 3-3 R2ee(0.5) & 3-3 R21ee(0.5) & & & & \\
\hline $0-1 \mathrm{R} 2 \mathrm{ff}(0.5)$ & $0-1 \mathrm{R} 21 \mathrm{ff}(0.5)$ & & & & \\
\hline $1-2 \mathrm{R} 2 \mathrm{ee}(0.5)$ & $1-2 \mathrm{R} 21 \mathrm{ee}(0.5)$ & & & & \\
\hline $1-2 \mathrm{P} 12 \mathrm{ee}(2.5)$ & NA & & & & \\
\hline 1-2 P12ff(2.5) & NA & & & & \\
\hline
\end{tabular}

Notes. NA stands for lines used in previous studies that we no longer consider in the constant determination process.

Table 2. Modified line assignments for the ${ }^{13} \mathrm{CH}$ transitions.

\begin{tabular}{|c|c|c|c|c|c|}
\hline \multicolumn{2}{|c|}{ Zachwieja (1997) A-X } & \multicolumn{2}{|c|}{ Para (1996) B-X } & \multicolumn{2}{|c|}{ Bembenek et al. (1997) C-X } \\
\hline $\begin{array}{l}\text { previous } \\
v^{\prime}-v^{\prime \prime} \mathrm{F}\left(J^{\prime \prime}\right)\end{array}$ & $\begin{array}{l}\text { new } \\
v^{\prime}-v^{\prime \prime} \mathrm{F}\left(J^{\prime \prime}\right)\end{array}$ & $\begin{array}{l}\text { previous } \\
v^{\prime}-v^{\prime \prime} \mathrm{F}\left(J^{\prime \prime}\right)\end{array}$ & $\begin{array}{l}\text { new } \\
v^{\prime}-v^{\prime \prime} \mathrm{F}\left(J^{\prime \prime}\right)\end{array}$ & $\begin{array}{l}\text { previous } \\
v^{\prime}-v^{\prime \prime} \mathrm{F}\left(J^{\prime \prime}\right)\end{array}$ & $\begin{array}{l}\text { new } \\
v^{\prime}-v^{\prime \prime} \mathrm{F}\left(J^{\prime \prime}\right)\end{array}$ \\
\hline $1-1 \mathrm{R} 2 \mathrm{ff}(0.5)$ & $1-1 \mathrm{R} 21 \mathrm{ee}(0.5)$ & $0-1 \mathrm{Q} 12 \mathrm{fe}(0.5)$ & $0-1 \mathrm{Q} 11 \mathrm{fe}(0.5)$ & $0-0$ R1ee $(0.5)$ & $0-0$ R12ee $(0.5)$ \\
\hline $1-1 \mathrm{R} 2 \mathrm{ee}(0.5)$ & $1-1 \mathrm{R} 21 \mathrm{ff}(0.5)$ & $0-1 \mathrm{R} 2 \mathrm{ee}(0.5)$ & $0-1 \mathrm{R} 21 \mathrm{ee}(0.5)$ & & \\
\hline $2-2 \mathrm{R} 2 \mathrm{ff}(0.5)$ & $2-2$ R21ee $(0.5)$ & $1-1$ R2ee $(0.5)$ & $1-1 \mathrm{R} 21 \mathrm{ee}(0.5)$ & & \\
\hline $2-2 \mathrm{R} 2 \mathrm{ee}(0.5)$ & 2-2 R21ff(0.5) & $1-1 \mathrm{Q} 12 \mathrm{fe}(0.5)$ & $1-1 \mathrm{Q} 11 \mathrm{fe}(0.5)$ & & \\
\hline $3-3 \mathrm{R} 2 \mathrm{ff}(0.5)$ & $3-3 \mathrm{R} 21 \mathrm{ee}(0.5)$ & $1-1 \mathrm{Q} 2 \mathrm{ef}(0.5)$ & $1-1 \mathrm{Q} 21 \mathrm{ef}(0.5)$ & & \\
\hline 3-3 R2ee(0.5) & $3-3 \mathrm{R} 21 \mathrm{ff}(0.5)$ & & & & \\
\hline $0-1 \mathrm{R} 2 \mathrm{ff}(0.5)$ & $0-1$ R21ee $(0.5)$ & & & & \\
\hline $0-1 \mathrm{R} 2 \mathrm{ee}(0.5)$ & $0-1 \mathrm{R} 21 \mathrm{ff}(0.5)$ & & & & \\
\hline $1-2 \mathrm{R} 2 \mathrm{ff}(0.5)$ & $1-2 \mathrm{R} 21 \mathrm{ee}(0.5)$ & & & & \\
\hline $1-2 \mathrm{R} 2 \mathrm{ee}(0.5)$ & $1-2 \mathrm{R} 21 \mathrm{ff}(0.5)$ & & & & \\
\hline 2-3 R2ff(0.5) & $2-3$ R21ee $(0.5)$ & & & & \\
\hline $2-3$ R2ee(0.5) & $2-3$ R21ff( $(0.5)$ & & & & \\
\hline
\end{tabular}

shallow flux depressions, in the middle of a forest of other atomic and molecular lines, were never previously identified as distinct spectral features.

Metal-poor stars, on the contrary, display much weaker atomic and molecular features, allowing a better estimate of the continuum level, and of possible deviations from it. It is therefore in the spectra of metal-poor stars, especially those with carbon-enrichment, that the weak and wide lines caused by $\mathrm{CH}$ predissociation are best seen.

Therefore, we use four stellar spectra: CS 22942-019 and HD 224959 both from VLT/UVES ranging from $3300 \AA$ to $5500 \AA$, HD 196944 also from VLT/UVES with a spectral coverage of 3050-3850 $\AA$ better suited for the analysis of the C-X band, and a Keck/HIRES spectrum of HE 2201-0345 from $3650 \AA$ to $4950 \AA$. The resolving power of these instruments, $R=\lambda / \Delta \lambda \approx 60000$, combined with the turbulent and thermal Doppler broadening of the lines, leads to an accuracy of typically $0.1 \AA$ in line positions, or about $0.5 \mathrm{~cm}^{-1}$ in these spectral ranges. The positions of the predissociation lines of the $\mathrm{B}-\mathrm{X}$ system are difficult to measure accurately as they are very broad and sometimes even diffuse. We estimate a $10 \mathrm{~cm}^{-1}$ uncertainty for them (see Sect. 4.1.3). The lines were weighted accordingly in PGopher fits. The four stars are cool metal-poor C-rich giants, with $T_{\text {eff }} \sim 5000 \mathrm{~K}$. Their spectra show strong 
T. Masseron et al.: $\mathrm{CH}$ in stellar atmospheres: an extensive linelist
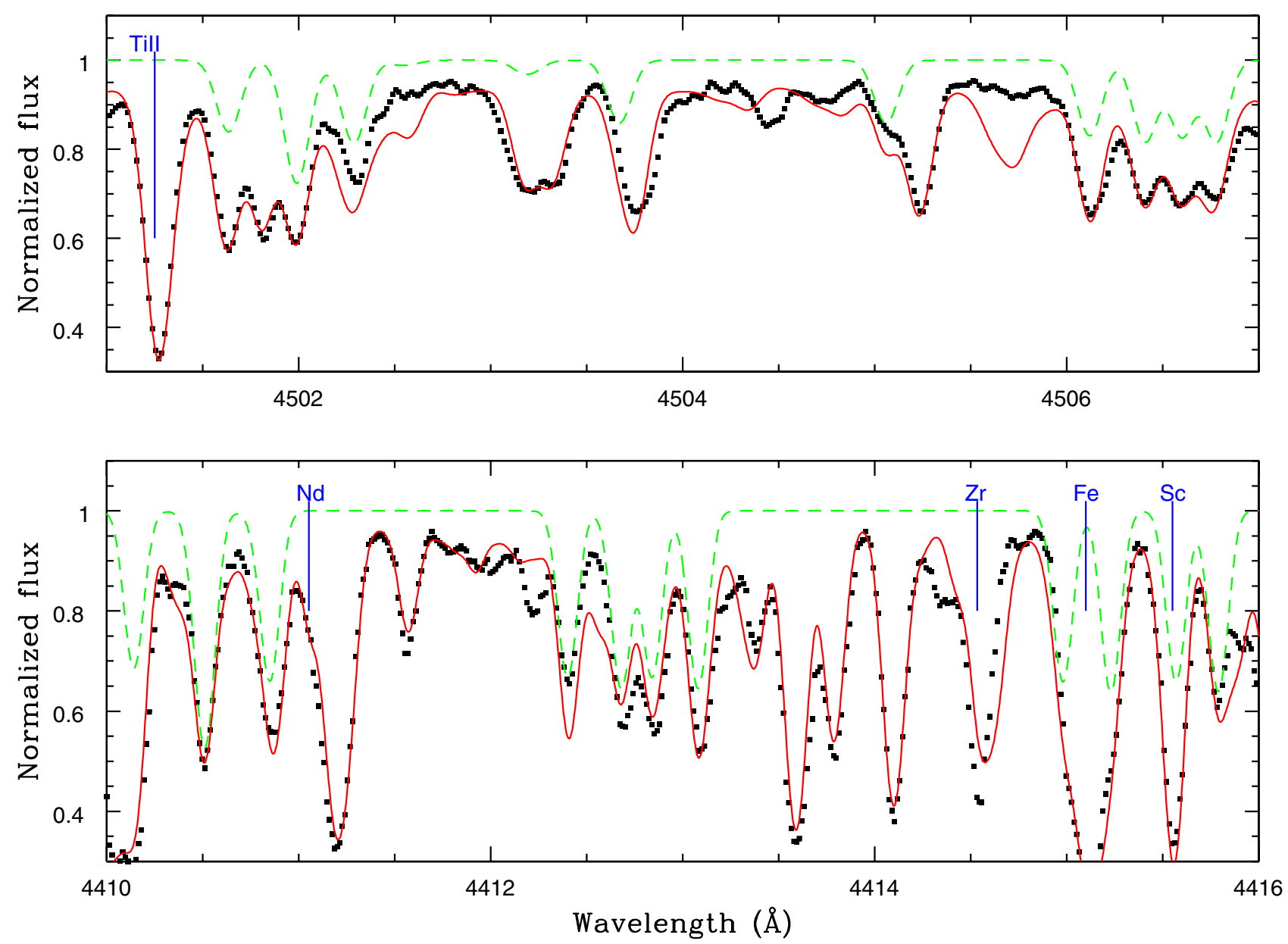

Fig. 2. Example of stellar spectrum syntheses in the $\mathrm{CH} A-\mathrm{X}$ transition region. The stellar spectrum is plotted with black points, the red continuous line is the synthesis including both atomic and molecular lines, and the green dashed line is the synthesis with only $\mathrm{CH}$ A-X 5-5 transitions in HE 2201-0345 (upper panel) and CH A-X 4-4 transitions in CS 22942-019 (lower panel) identified for the first time in a spectrum. We note that some of the mismatches between the synthesis and the observation (e.g. $4505.7 \AA, 4412 \AA$ ) can be attributed to inaccuracies of other atomic or molecular linelists.

$\mathrm{CH}$ features, but they are only weakly blended by atomic lines. While CS 22942-019 and HE 2201-0345 have ${ }^{12} \mathrm{C} /{ }^{13} \mathrm{C}$ ratios around 10, HD 196944 and HD 224959 have a carbon isotopic ratio of 4 to 5 , allowing an easier identification of ${ }^{13} \mathrm{CH}$ lines. The blending of $\mathrm{CH}$ features by other atomic and molecular features may lead to confusion. Therefore we strive to also reproduce the line intensities in order to resolve ambiguities (see Fig. 2). Our MARCS (Gustafsson et al. 2008) model atmospheres were specifically tailored to take into account the specific chemical composition (notably $\mathrm{C}$ and $\mathrm{O}$ ), because this affects the thermodynamical structure (see the discussion in Masseron 2006). The elemental abundances are from Masseron et al. (2010) (except for HE 2201-0345, Masseron et al., in prep.). They are listed in Table 3 . We note that ${ }^{13} \mathrm{CH}$ lines are always weaker than the corresponding ${ }^{12} \mathrm{CH}$ lines, because ${ }^{13} \mathrm{C}$ is always less abundant than ${ }^{12} \mathrm{C}$. Line identifications could only be made for the strongest ${ }^{13} \mathrm{CH}$ lines, limiting the number of molecular constants we could derive.

The positions of newly identified lines of the ${ }^{12} \mathrm{CH} \mathrm{A}-\mathrm{X}$, $\mathrm{B}-\mathrm{X}$, and $\mathrm{C}-\mathrm{X}$ transitions in our stellar spectra are reported in Tables A.2-A.4, while those for ${ }^{13} \mathrm{CH}$ are reported in Tables A.5-A.7.

For the A-X transition, we observed levels up to $J^{\prime \prime}=36.5$ for $v^{\prime}=0, J^{\prime \prime}=32.5$ for $v^{\prime}=1, J^{\prime \prime}=31.5$ for $v^{\prime}=2$, and $J^{\prime \prime}=27.5$ for $v^{\prime}=3$, very close to the dissociation limit, while only levels up to $J^{\prime \prime}=27.5$ for $v^{\prime}=0, J^{\prime \prime}=19.5$ for $v^{\prime}=1$, $J^{\prime \prime}=12.5$ for $v^{\prime}=2$, and $J^{\prime \prime}=10.5$ for $v^{\prime}=3$ were measured by Zachwieja (1995). We were able to determine for the first time the constants for the $\mathrm{A}^{2} \Delta v=4$ and $v=5$ states. For the B-X transition (Table A.3), we observed transitions from higher $J^{\prime \prime}$ levels than Kepa (1996) and Bernath et al. (1991; $\left.J^{\prime \prime}<15.5\right)$, and than Kumar et al. (1998; $\left.J^{\prime \prime}<21.5\right)$. For the $\mathrm{C}-\mathrm{X}$ transition, we also observe lines to higher rotational levels in our CEMP star spectrum than in laboratory spectra. There is an excellent agreement with the predicted line positions derived from the laboratory experiments.

\section{Results}

\subsection{Revised molecular constants for ${ }^{12} \mathrm{CH}$}

After merging all data of all transitions (i.e. ro-vibrational, A-X, $\mathrm{B}-\mathrm{X}$, and $\mathrm{C}-\mathrm{X}$ ) from laboratory and from stellar spectra observations into PGopher, weighted according to their respective accuracy, we were able to derive a single set of new molecular constants for the four lowest doublet electronic states of $\mathrm{CH}$. The constants we provide in this section are consistent with the definition of the Hamiltonian of Brown et al. (1979): $B_{v}$ is the rotational constant; $D_{v}, H_{v}, L_{v}$, and $M_{v}$ are the centrifugal distortion constants. $A_{v}$ is the spin-orbit constant; $\gamma_{v}$ and $\gamma_{D v}$ are the spin-rotation constant and its centrifugal distortion; 
Table 3. Adopted stellar parameters and abundances for the sample stars.

\begin{tabular}{lcccc}
\hline \hline & HD 196944 & HD 224959 & CS 22942-019 & HE 2201-0345 \\
\hline$T_{\text {eff }}$ & 5250 & 4900 & 5100 & 4800 \\
$\log g$ & 1.7 & 2.0 & 2.5 & 1.9 \\
{$[\mathrm{Fe} / \mathrm{H}]$} & -2.25 & -2.10 & -2.50 & -2.10 \\
{$[\alpha / \mathrm{Fe}]$} & +0.40 & +0.40 & +0.40 & +0.40 \\
$\log \mathrm{A}(\mathrm{C})$ & 7.35 & 8.15 & 8.10 & 7.95 \\
${ }^{12} \mathrm{C} /{ }^{13} \mathrm{C}$ & 5 & 4 & 12 & 10 \\
$\log \mathrm{A}(\mathrm{N})$ & 7.05 & 7.60 & 6.40 & 6.70 \\
$\log \mathrm{A}(\mathrm{O})$ & 6.8 & 7.7 & 6.7 & 7.5 \\
{$[\mathrm{Sr}, \mathrm{Y}, \mathrm{Zr}, \mathrm{Ba}, \mathrm{La}, \mathrm{Pb} / \mathrm{Fe}]$} & 1.5 & 2.0 & 1.5 & 1.3 \\
\hline
\end{tabular}

and $p_{v}$ and $q_{v}$ are the $\Lambda$-doubling constants. For the computation of Einstein coefficients and level radiative lifetime, we used the electronic-transition moments of van Dishoeck (1987). For the ro-vibrational transitions, we used the dipole moment function calculated by Hettema \& Yarkony (1994). We scaled the electronic-transition moments to match the experimental lifetime measurements: $\tau_{00}=535 \mathrm{~ns}$ for the $\mathrm{A}^{2} \Delta v=0$ level (Luque \& Crosley 1996a), $\tau_{00}=325 \mathrm{~ns}$ for the $\mathrm{B}^{2} \Sigma^{-} v=0$ level (Luque \& Crosley 1996b), and $\tau_{00}=110 \mathrm{~ns}$ for the $\mathrm{C}^{2} \Sigma^{+} v=0$ level (Brzozowski et al. 1976).

\subsubsection{The $X^{2} \Pi$ fundamental state}

Thanks to the supplementary data offered by our spectra in the optical region, we could improve the ground state constants. The constants we obtained are presented in Table 4. They are consistent with the work of Colin \& Bernath (2010), as we included their data in our fit. Moreover, thanks to our observations of high $J$ A-X transitions (see Fig. 2), we could improve the accuracy of the high-order constants, notably of $L_{v}$.

\subsubsection{The $A^{2} \Delta$ state}

Table 5 contains the constants we derive for the $\mathrm{A}^{2} \Delta$ state. We were able to determine for the first time the constants for the $\mathrm{A}^{2} \Delta v=4$ and 5 levels (Fig. 2). For the lower vibrational levels, our constants agree well with the ones of Zachwieja (1995) because we used of their laboratory measurements. The small differences come from the fact that we obtained different constants for the ground state. However, in contrast to Zachwieja (1995), we could not recover the $\Lambda$-doubling constants $p_{v}$ and $q_{v}$ similar to Bernath et al. (1991). The resulting rms difference of the observed minus calculated line positions is $1.46 \times 10^{-2} \mathrm{~cm}^{-1}$, which is very satisfactory for studies of stellar spectra. Because some of the A levels are expected to predissociate (see Sect. 2), their lifetime should be shorter than their radiative lifetime (Brzozowski et al. 1976). However, we did not observe any increased broadening for the $\mathrm{A}-\mathrm{X}$ lines in our stellar spectra. The predissociation broadening is dominated by thermal and turbulence broadening in our target stars. Nevertheless, the predissociation lifetimes are included in our linelist.

\subsubsection{The $\mathrm{B}^{2} \Sigma^{-}$state}

Table 6 presents the constants we have derived for the $\mathrm{B}^{2} \Sigma^{-}$state. The constants are in good agreement with Kepa (1996).

There are a number of high $J \mathrm{~B}-\mathrm{X}$ predissociation lines that can be seen even in the solar spectrum (Fig. 3). However, as already noted by Kumar et al. (1998), their positions are not well
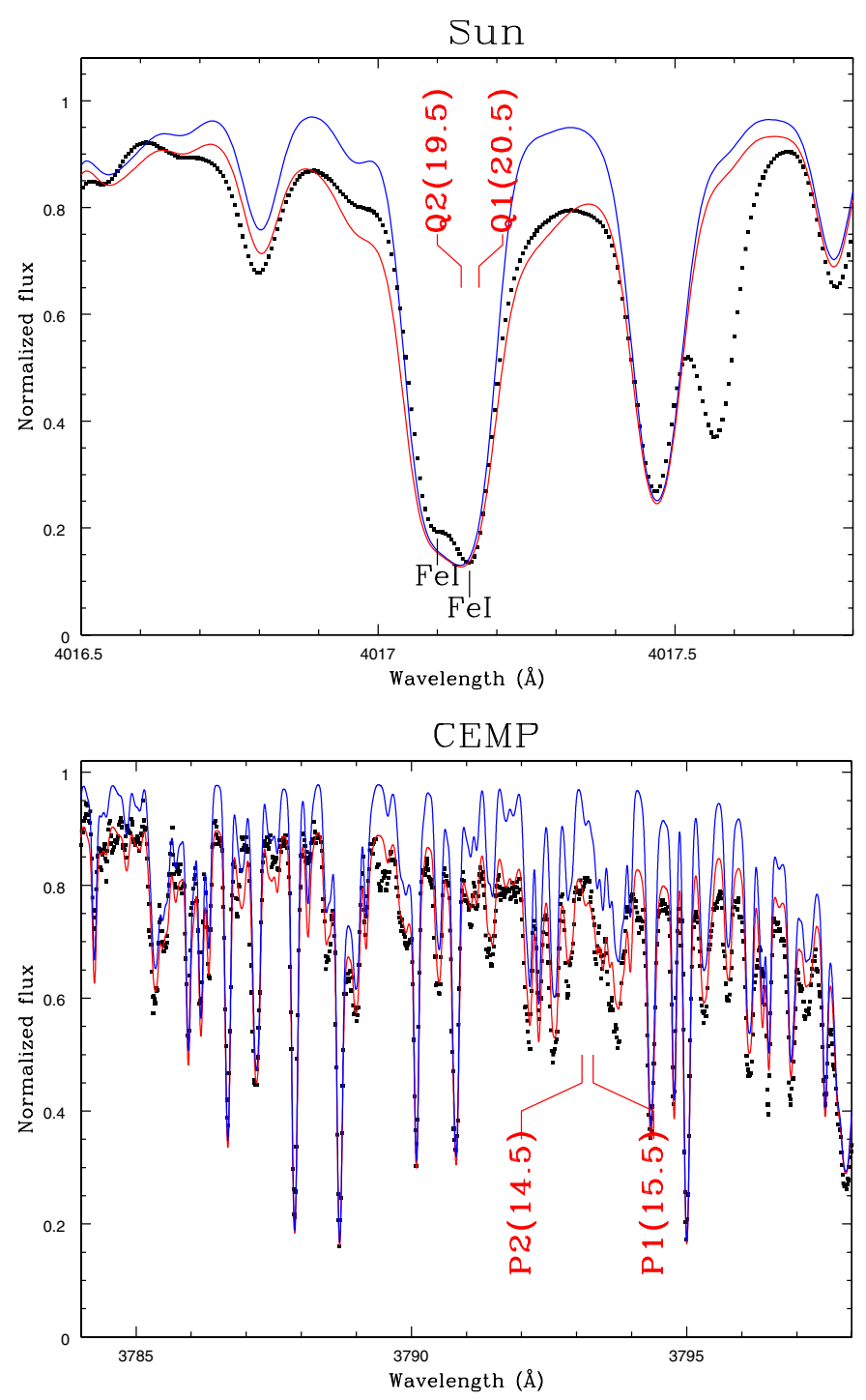

Fig. 3. Top panel: example of a synthesis of the solar photospheric spectrum (dotted black) including (red) and omitting (blue) predissociation lines of the B-X system. Bottom panel: Same for the CEMP star CS 22942-019. Predissociation lines, as well as many other CH lines, are present and contribute to the flux depression. In the case of the CEMP star, the presence of several extremely broad $\mathrm{CH}$ predissociation lines is so important that it acts as a pseudo-continuum.

defined. These lines do not help to improve the accuracy of the B state constants, but nevertheless we include them in our final linelist. Predissociative lifetimes of the corresponding levels are listed in Table 7. They are in good agreement with the laboratory 
T. Masseron et al.: $\mathrm{CH}$ in stellar atmospheres: an extensive linelist

Table 4. Constants (in $\mathrm{cm}^{-1}$ ) for the $\mathrm{X}^{2} \Pi$ state of ${ }^{12} \mathrm{CH}$.

\begin{tabular}{lllllll}
\hline \hline Constant & $v=0$ & $v=1$ & $v=2$ & $v=3$ & $v=4$ & $v=5$ \\
\hline$T_{v}$ & 0.0 & $2732.97900(130)$ & $5339.9051(20)$ & $7822.2222(28)$ & $10181.0060(41)$ & $12416.755(24)$ \\
& 0.0 & $2732.97813(94)$ & $5339.9036(15)$ & $7822.2184(18)$ & $10180.9996(22)$ & $12416.786(10)$ \\
$B_{v}$ & $14.192249(57)$ & $13.6617020(560)$ & $13.135783(58)$ & $12.613439(67)$ & $12.092930(100)$ & $11.57387(52)$ \\
& $14.192393(61)$ & $13.6617896(53)$ & $13.135809(50)$ & $12.613441(50)$ & $12.092993(54)$ & $11.57300(23)$ \\
$A_{v}$ & $28.14675^{a}$ & $28.33833^{a}$ & $28.5312(78)$ & $28.652(14)$ & $28.909(30)$ & $28.64(49)$ \\
$\gamma_{v} \times 10^{2}$ & $28.14675^{a}$ & $28.33833^{a}$ & $28.6160(510)$ & $28.765(48)$ & $28.968(45)$ & $29.17^{b}$ \\
& $-2.624(33)$ & $-2.424(32)$ & $-2.267(37)$ & $-2.136(46)$ & $-1.954(62)$ & $-1.86(16)$ \\
$p_{v} \times 10^{2}$ & $-2.853(86)$ & $-2.654(85)$ & $-2.462(83)$ & $-2.323(81)$ & $-2.138(80)$ & $-1.933(70)$ \\
& $3.358(29)$ & $3.174(24)$ & $3.085(34)$ & $2.987(48)$ & $2.779(95)$ & $2.580(150)$ \\
$q_{v} \times 10^{2}$ & $3.464(36)$ & $3.260(34)$ & $3.119(36)$ & $2.967(42)$ & $2.836(52)$ & $2.673(62)$ \\
& $3.8684(20)$ & $3.7290(17)$ & $3.5902(23)$ & $3.4487(35)$ & $3.3104(69)$ & $3.1724(75)$ \\
$D_{v} \times 10^{3}$ & $3.8660(31)$ & $3.7285(29)$ & $3.5919(32)$ & $3.4541(36)$ & $3.3179(43)$ & $3.1776(32)$ \\
& $1.46079(32)$ & $1.43776(32)$ & $1.41641(32)$ & $1.39722(35)$ & $1.37980(56)$ & $1.3740(25)$ \\
$H_{v} \times 10^{7}$ & $1.46112(37)$ & $1.43742(31)$ & $1.41553(31)$ & $1.39612(32)$ & $1.37911(35)$ & $1.3692(11)$ \\
& $1.1381(71)$ & $1.1061(68)$ & $1.0717(64)$ & $1.0295(64)$ & $0.953(10)$ & $0.90^{b}$ \\
$L_{v} \times 10^{12}$ & $1.1064(75)$ & $1.0625(85)$ & $1.0212(97)$ & $0.9790(100)$ & $0.917(10)$ & $0.88^{b}$ \\
& $-12.00(54)$ & $-12.12(47)$ & $-12.65(41)$ & $-13.52(37)$ & $-13.48(68)$ & $-13.5^{b}$ \\
$p_{D v} \times 10^{5}$ & $-3.40(177)$ & $-4.34(162)$ & $-5.69(147)$ & $-7.55(129)$ & $-9.27(111)$ & $-11.6^{b}$ \\
& $-0.853(79)$ & $-0.728(68)$ & $-0.685(71)$ & $-0.532(91)$ & $-0.52(17)$ & $-0.6^{b}$ \\
$q_{D v} \times 10^{5}$ & $-1.010(370)$ & $-0.840(340)$ & $-0.730(320)$ & $-0.630(290)$ & $-0.60(27)$ & $-0.55^{b}$ \\
& $-1.524(10)$ & $-1.4865(94)$ & $-1.4453(94)$ & $-1.394(12)$ & $-1.344(26)$ & $-1.35^{b}$ \\
$q_{H v} \times 10^{9}$ & $-1.590(20)$ & $-1.5500(220)$ & $-1.5090(240)$ & $-1.461(24)$ & $-1.4090(25)$ & $-1.35^{b}$ \\
& $3.08(13)$ & $2.94(11)$ & $2.790(10)$ & $2.60(11)$ & $2.30(24)$ & $2.0^{b}$ \\
$\gamma_{D v} \times 10^{5}$ & $4.06(57)$ & $3.79(53)$ & $3.560(480)$ & $3.30(42)$ & $2.90(37)$ & $2.52^{b}$ \\
& $0.99(15)$ & $0.90(14)$ & $0.88(13)$ & $0.91(13)$ & $0.81(14)$ & $0.8^{b}$ \\
& $1.78(24)$ & $1.64(22)$ & $1.53(21)$ & $1.50(19)$ & $1.33(18)$ & $1.29^{b}$ \\
\hline
\end{tabular}

Notes. Uncertainties in parentheses are one standard deviation in units of the last quoted digit. The second line contains the values of Colin \& Bernath (2010). ${ }^{(a)}$ Fixed to Jackson et al. (2008). ${ }^{(b)}$ Kept fixed.

Table 5. Constants (in $\mathrm{cm}^{-1}$ ) for the $\mathrm{A}^{2} \Delta$ state.

\begin{tabular}{|c|c|c|c|c|c|c|}
\hline Constant & $v=0$ & $v=1$ & $v=2$ & $v=3$ & $v=4$ & $v=5$ \\
\hline \multirow[t]{2}{*}{$T_{v}$} & $23173.45580(110)$ & $25913.7404(21)$ & $28460.7224(32)$ & $30794.1049(45)$ & $32885.355(84)$ & $34695.691(73)$ \\
\hline & $23173.45853(56)^{a}$ & $25913.7454(11)^{a}$ & $28460.7406(24)^{a}$ & $30794.1115(20)^{a}$ & & \\
\hline \multirow{2}{*}{$B_{v}$} & $14.579064(58)$ & $13.911205(75)$ & $13.18806(11)$ & $12.37277(17)$ & $11.4667(21)$ & $10.33371(21)$ \\
\hline & $14.579083(47)^{a}$ & $13.910878(60)^{a}$ & $13.18663(12)^{a}$ & $12.38208(11)^{a}$ & & \\
\hline \multirow[t]{2}{*}{$D_{v} \times 10^{3}$} & $1.56621(34)$ & $1.60903(46)$ & $1.6909(11)$ & $1.8275(21)$ & $2.171(15)$ & $2.455(19)$ \\
\hline & $1.56604(30)^{a}$ & $1.60408(88)^{a}$ & $1.6689(12)^{a}$ & $1.8157(12)^{a}$ & & \\
\hline \multirow{2}{*}{$H_{v} \times 10^{8}$} & $9.962(61)$ & $8.94(11)$ & $8.60(27)$ & $6.30(62)$ & $32.5(38)$ & $-38.9(53)$ \\
\hline & $9.761(72)^{a}$ & $6.98(46)^{a}$ & & & & \\
\hline \multirow[t]{2}{*}{$L_{v} \times 10^{11}$} & $-2.817(33)$ & $-5.274(69)$ & $-11.88(17)$ & $-20.634(50)$ & $-93.2(32)$ & $-127.2(30)$ \\
\hline & $2.666(55)^{a}$ & $3.09(77)^{a}$ & & & & \\
\hline \multirow[t]{2}{*}{$A_{v}$} & $-1.10150(140)$ & $-1.0721(20)$ & $-1.0402(26)$ & $-0.9934(38)$ & $-0.95^{b}$ & $-0.9^{b}$ \\
\hline & $-1.10088(88)^{a}$ & $-1.0697(13)^{a}$ & $-1.0392(27)^{a}$ & $-0.9982(27)^{a}$ & & \\
\hline \multirow[t]{2}{*}{$\gamma_{v} \times 10^{2}$} & $4.171(37)$ & $3.979(49)$ & $3.821(53)$ & $3.370(75)$ & $3.21(27)$ & $3.0^{b}$ \\
\hline & $4.217(25)^{a}$ & $4.000(20)^{a}$ & $3.778(44)^{a}$ & $3.518(37)^{a}$ & & \\
\hline \multirow[t]{2}{*}{$\gamma_{D v} \times 10^{5}$} & $-0.730(150)$ & $-0.790(270)$ & & & & \\
\hline & $-0.925(65)^{a}$ & $-0.871(92)^{a}$ & & & & \\
\hline$p_{v} \times 10^{\prime}$ & $6.6(14)^{a}$ & $13.0(74)^{a}$ & $28(11)^{a}$ & $58(88)^{a}$ & & \\
\hline \multirow{2}{*}{$q_{v} \times 10^{8}$} & $4.53(88)$ & $14.1(53)$ & & & & \\
\hline & $-2.89(36)^{a}$ & $-17.5(24)^{a}$ & $-35 .(52)^{a}$ & $-133 .(60)^{a}$ & & \\
\hline
\end{tabular}

Notes. Uncertainties in parentheses are one standard deviation in units of the last quoted digit. ${ }^{(a)}$ Constants by Zachwieja (1995). ${ }^{(b)}$ Kept fixed.

observations of Kumar et al. (1998), and Luque \& Crosley (1996b). Because of the increasing broadening of the lines with rotational quantum number, the identification of the lines becomes more and more uncertain as $J$ increases. Consequently, the identification of some levels is ambiguous and the exact dissociation energy of the B state is very difficult to determine. We set the height of the predissociation barrier according to our new line identifications, that include the observed 0-0 R1(21.5) line, with an upper energy level of $31474 \mathrm{~cm}^{-1}$. The height of the barrier is thus at least 31 474-29374 $=2100 \mathrm{~cm}^{-1}$, with $D_{\mathrm{e}}=29374 \pm 10 \mathrm{~cm}^{-1}$ (Kumar et al. 1998), almost twice as high as the value of $1150 \mathrm{~cm}^{-1}$ predicted by van Dishoeck (1987).

Assuming this barrier height, $\mathrm{B}^{2} \Sigma^{-} v=1$ levels have been included up to $J^{\prime \prime}=20.5$ in our list, although we were able to identify B-X transitions only up to $J^{\prime \prime}=16.5$ because the combination of low $g f$ values and large predissociation broadening 
Table 6. Constants (in $\mathrm{cm}^{-1}$ ) for the $\mathrm{B}^{2} \Sigma^{-}$state.

\begin{tabular}{lll}
\hline \hline Constant & $v=0$ & $v=1$ \\
\hline$T_{v}$ & $25712.5074(24)$ & $27507.5216(24)$ \\
& $25712.5113(12)^{a}$ & $27507.5250(8)^{a}$ \\
$B_{v}$ & $12.640320(220)$ & $11.15815(48)$ \\
& $12.640159(66)^{a}$ & $11.15788(14)^{a}$ \\
$D_{v} \times 10^{3}$ & $2.13110(560)$ & $3.1680(260)$ \\
& $2.12954(94)^{a}$ & $3.1260(60)^{a}$ \\
$H_{v} \times 10^{7}$ & $-4.930(540)$ & $-14.90(500)$ \\
& $-4.114(36)^{a}$ & $-30.22(74)^{a}$ \\
$L_{v} \times 10^{10}$ & $9.7(21)$ & 0.0 \\
& $0.0^{a}$ & $0.0^{a}$ \\
$M_{v} \times 10^{12}$ & $-2.70(27)$ & 0.0 \\
& $0.0^{a}$ & $0.0^{a}$ \\
$\gamma_{v} \times 10^{2}$ & $-2.938(47)$ & $-2.1(46)$ \\
& $-2.702(16)^{a}$ & $-2.216(13)^{a}$ \\
$\gamma_{D v} \times 10^{5}$ & $2.08(39)$ & $0.0^{a}$ \\
& $0.0^{a}$ & $0.0^{a}$ \\
\hline
\end{tabular}

Notes. Uncertainties in parentheses are one standard deviation in units of the last quoted digit. ${ }^{(a)}$ Constants derived by Kepa (1996).

Table 7. Radiative lifetimes from this work and experimental lifetimes from Luque \& Crosley (1996b) of the $\mathrm{B}^{2} \Sigma^{-}$levels in ns.

\begin{tabular}{|c|c|c|c|c|}
\hline & \multicolumn{2}{|c|}{$\overline{v e=0}$} & \multicolumn{2}{|c|}{ 作 } \\
\hline$J$ & $\overline{\tau_{\text {rad }}}$ & $\tau_{\exp }$ & $\tau_{\mathrm{rad}}$ & $\tau_{\exp }$ \\
\hline 0.5 & 328 & & 472 & \\
\hline 1.5 & 329 & & 474 & \\
\hline 2.5 & 330 & 328 & 476 & \\
\hline 3.5 & 332 & 345 & 480 & 396 \\
\hline 4.5 & 335 & 328 & 486 & 410 \\
\hline 5.5 & 338 & 346 & $\begin{array}{l}493 \\
\text { pred }\end{array}$ & $\begin{array}{r}405 \\
\text { tion onset }\end{array}$ \\
\hline 6.5 & 343 & 356 & 502 & 390 \\
\hline 7.5 & 348 & 354 & 512 & 5.0 \\
\hline 8.5 & 354 & 360 & 526 & 0.350 \\
\hline 9.5 & 361 & 345 & 543 & 0.075 \\
\hline 10.5 & 370 & 352 & 563 & 0.015 \\
\hline 11.5 & 380 & 364 & 589 & 0.005 \\
\hline 12.5 & 392 & 362 & 620 & 0.0013 \\
\hline 13.5 & 406 & 395 & & 0.0004 \\
\hline 14.5 & $\begin{array}{l}423 \\
\text { prec }\end{array}$ & $\begin{array}{r}435 \\
n \text { onset }\end{array}$ & & $0.0002^{a}$ \\
\hline 15.5 & 443 & 140 & & $0.00001^{a}$ \\
\hline 16.5 & 468 & 70 & & $0.000003^{a}$ \\
\hline 17.5 & 498 & 0.6 & & $1.0 \mathrm{E}-6^{a}$ \\
\hline 18.5 & 535 & 0.045 & & $3.0 \mathrm{E}-7^{a}$ \\
\hline 19.5 & 582 & 0.010 & & $1.0 \mathrm{E}-7^{a}$ \\
\hline 20.5 & 642 & 0.003 & & $3.0 \mathrm{E}-8^{a}$ \\
\hline 21.5 & 723 & 0.0004 & & \\
\hline & & edissoci & $n b$ & \\
\hline
\end{tabular}

Notes. (a) Extrapolated value from astrophysical observations. Predissociation onset is the limit of the lowest level with evidence for predissociation and predissociation barrier indicates the limit of the uppest level with evidencce for predissociation.

limits the identification. However, we stress that these very broad lines act as a pseudo-continuum and must be taken into account in spectrum synthesis (see Fig. 3).

An atlas of predissociation lines for some typical spectra (the Sun, Arcturus, and several carbon-enhanced metal-poor stars) is presented in the appendix.



Fig. 4. Observed solar photospheric spectrum (black dots) and synthetic spectra using the former CX linelist (blue dotted line) from Jorgensen et al. (1996) and our C-X linelist (red solid line).

\subsubsection{The $\mathrm{C}^{2} \Sigma^{+}$state}

We were able to identify $\mathrm{C}-\mathrm{X}$ lines in our CEMP star spectrum at higher $J$ than in any published laboratory works so far. As shown in Table 8, there is an excellent agreement of their measured positions with the predicted values derived from the laboratory constants. As our identifications carry a lower accuracy than laboratory measurements, we did not attempt to use these lines in our global fit. However, thanks to the inclusion of more recent laboratory data from Li et al. (1999) and Bembenek et al. (1997) compared to Jorgensen et al. (1996), we were able to improve the C-X linelist (see Fig. 4).

The $\mathrm{C}$ state is also known to predissociate, but the predissociation lifetimes are larger than for the B state (Brzozowski et al. 1976). We could not detect any increase in the line broadening in our stellar spectra, but we nevertheless include the broadening lifetime in our list using the corresponding predissociation lifetime measurements of Brzozowski et al. (1976) and Ubachs et al. (1986).

\subsection{Revised molecular constants for ${ }^{13} \mathrm{CH}$}

Tables 9-12 present the molecular constants we derive for the four lowest doublet electronic states of ${ }^{13} \mathrm{CH}$. The experimental data were taken from Zachwieja (1997), Para (1996), and Bembenek et al. (1997; see Sect. 3.2). Because the abundance of ${ }^{13} \mathrm{C}$ is lower than ${ }^{12} \mathrm{C}$ in stellar atmospheres, we were not able to observe transitions to much higher $J$ values than in the laboratory, as we did for ${ }^{12} \mathrm{CH}$. Although the lines observed in stellar spectra contribute to improve the accuracy of high-order $J$ constants, the major improvements in the constants come from our global fit of all the laboratory data for the three electronic transitions ( $\mathrm{A}-\mathrm{X}, \mathrm{B}-\mathrm{X}$, and $\mathrm{C}-\mathrm{X})$, which had never been done previously; for example we were able to recover experimentally for the first time the spin-orbit constant $\left(A_{v}\right)$ of the fundamental level (Table 9).

We were also able detect for the first time predissociation lines for the B state of ${ }^{13} \mathrm{CH}$. Because the potential and the energy levels are not strictly identical to the ${ }^{12} \mathrm{CH}$ case, predissociation may occur for other levels and with different lifetimes. The quality of our spectra, the presence of blends with other 
Table 8. Constants $\left(\right.$ in $\mathrm{cm}^{-1}$ ) for the $\mathrm{C}^{2} \Sigma^{+}$state.

\begin{tabular}{llll}
\hline \hline Constant & $v=0$ & $v=1$ & $v=2$ \\
\hline$T_{v}$ & $31791.6479(16)$ & $34403.310(21)$ & $36772.842(54)$ \\
& $31791.6467(8)^{a}$ & $34403.106(21)^{a}$ & $36772.825(24)^{a}$ \\
$B_{v}$ & $14.255724(90)$ & $13.50577(43)$ & $12.6046(29)$ \\
& $14.255908(10)^{a}$ & $13.51614(66)^{a}$ & $12.6076(18)^{a}$ \\
$D_{v} \times 10^{3}$ & $1.59375(97)$ & $1.6336(21)$ & $1.918(37)$ \\
& $1.59511(46)^{a}$ & $1.7305(55)^{a}$ & $2.013(27)^{a}$ \\
$H_{v} \times 10^{8}$ & $7.45(29)$ & $-14.7(27)$ & $-73 .(10)$ \\
& $7.67(14)^{a}$ & $14.7(16)^{a}$ & $0.0^{a}$ \\
$L_{v} \times 10^{11}$ & $-3.75(26)$ & 0.0 & 0.0 \\
& $-3.73(12)^{a}$ & $-28.1(15)^{a}$ & $0.0^{a}$ \\
$\gamma_{v} \times 10^{2}$ & $4.126(58)$ & $3.320(120)$ & $3.80(10)$ \\
& $4.320(32)^{a}$ & $3.650(250)^{a}$ & $3.53(43)^{a}$ \\
$\gamma_{D v} \times 10^{5}$ & $-1.66(62)$ & 0.0 & 0.0 \\
& $-3.86(51)^{a}$ & $-1.32(75)^{a}$ & $0.0^{a}$ \\
$\gamma_{H v} \times 10^{8}$ & 0.0 & 0.0 & 0.0 \\
& $3.09(87)^{a}$ & $0.0^{a}$ & $0.0^{a}$ \\
\hline
\end{tabular}

Notes. Uncertainties in parentheses are one standard deviation in units of the last quoted digit. ${ }^{(a)}$ Values from Li et al. (1999).

Table 9. Constants (in $\mathrm{cm}^{-1}$ ) for the $\mathrm{X}^{2} \Pi$ state of ${ }^{13} \mathrm{CH}$.

\begin{tabular}{|c|c|c|c|c|}
\hline Constant & $v=0$ & $v=1$ & $v=2$ & $v=3$ \\
\hline \multirow[t]{2}{*}{$T_{v}$} & 0.0 & $2725.1667(24)$ & $5325.0275(46)$ & $7801.0058(58)$ \\
\hline & 0.0 & $2725.1644(12)^{a}$ & $5325.0249(19)^{a}$ & $7800.9918(48)^{a}$ \\
\hline \multirow[t]{2}{*}{$B_{v}$} & $14.108424(100)$ & $13.582530(110)$ & $13.061290(190)$ & $12.54273(26)$ \\
\hline & $14.108210(43)^{a}$ & $13.582435(43)^{a}$ & $13.061122(62)^{a}$ & $12.54347(19)^{a}$ \\
\hline \multirow[t]{2}{*}{$A_{v}$} & $28.1426(81)$ & $28.3355(87)$ & $28.508(21)$ & 28.701(13) \\
\hline & $28.14643^{a, b}$ & $28.3384^{a, b}$ & $28.5243^{a, b}$ & $28.7041^{a, b}$ \\
\hline \multirow{2}{*}{$\gamma_{v} \times 10^{2}$} & $-2.514(59)$ & $-2.308(53)$ & $-2.146(66)$ & $-1.96(13)$ \\
\hline & $-2.547(22)^{a}$ & $-2.363(20)^{a}$ & $-2.177(27)^{a}$ & $-2.0728^{a, b}$ \\
\hline \multirow{2}{*}{$p_{v} \times 10^{2}$} & $3.304^{c}$ & $3.243(59)$ & $2.969(51)$ & $2.665(98)$ \\
\hline & $3.313(15)^{a}$ & $3.190(13)^{a}$ & $3.019(30)^{a}$ & $2.843(62)^{a}$ \\
\hline \multirow[t]{2}{*}{$q_{v} \times 10^{2}$} & $3.823672^{c}$ & $3.6916(65)$ & $3.5491(85)$ & $3.4060(150)$ \\
\hline & $3.8190(12)^{a}$ & $3.6849(12)^{a}$ & $3.5521(18)^{a}$ & $3.4163(40)^{a}$ \\
\hline \multirow[t]{2}{*}{$D_{v} \times 10^{3}$} & $1.44443(72)$ & $1.42004(84)$ & $1.40030(270)$ & $1.3607(27)$ \\
\hline & $1.44440(29)^{a}$ & $1.42186(32)^{a}$ & $1.40001(43)^{a}$ & $1.3787(17)^{a}$ \\
\hline \multirow[t]{2}{*}{$H_{v} \times 10^{7}$} & $1.1380(180)$ & $1.0240(190)$ & $1.08(11)$ & $1.0^{b}$ \\
\hline & $1.1457(68)^{a}$ & $1.1272(66)^{a}$ & $1.0731^{a, b}$ & $1.0284^{a, b}$ \\
\hline \multirow[t]{2}{*}{$L_{v} \times 10^{11}$} & $-1.36(14)$ & 0.0 & 0.0 & 0.0 \\
\hline & $1.426(52)^{a}$ & $1.386^{a, b}$ & $1.397^{a, b}$ & $1.446^{a, b}$ \\
\hline \multirow{2}{*}{$p_{D v} \times 10^{6}$} & $-8.51(56)$ & $-12.6(36)$ & 0.0 & 0.0 \\
\hline & $-8.91(40)^{a}$ & $-7.92^{a, b}$ & $-6.93^{a, b}$ & $-5.94^{a, b}$ \\
\hline \multirow{2}{*}{$q_{D v} \times 10^{5}$} & $-1.5100(63)$ & $-1.604(71)$ & $-1.373(85)$ & 0.0 \\
\hline & $-1.4792(64)^{a}$ & $-1.4448(52)^{a}$ & $-1.4101^{a, b}$ & $-1.3717^{a, b}$ \\
\hline \multirow[t]{2}{*}{$q_{H v} \times 10^{9}$} & $3.110(120)$ & $7.0(17)$ & 0.0 & 0.0 \\
\hline & $2.724(81)^{a}$ & $2.673^{a, b}$ & $2.580^{a, b}$ & $2.488^{a, b}$ \\
\hline \multirow[t]{2}{*}{$\gamma_{D v} \times 10^{6}$} & $5.8(22)$ & 0.0 & 0.0 & 0.0 \\
\hline & $8.45(74)^{a}$ & $8.185^{a, b}$ & $8.135^{a, b}$ & $8.354^{a, b}$ \\
\hline
\end{tabular}

Notes. Uncertainties in parentheses are one standard deviation in units of the last quoted digit. ${ }^{(a)}$ Constants derived by Zachwieja (1997). ${ }^{(b)}$ Kept fixed. ${ }^{(c)}$ Taken from Steimle et al. (1986).

lines, and the diffuse character of the predissociation lines did not allow us to measure any significant difference in the widths of the predissociated lines of ${ }^{12} \mathrm{CH}$ and ${ }^{13} \mathrm{CH}$. Therefore, the same predissociation lifetimes as for ${ }^{12} \mathrm{CH}$ were adopted. For the $\mathrm{C}$ state, only the constants for the $v=0$ level could be determined as we could not assign any lines linking to other vibrational levels. Improvements of the ${ }^{13} \mathrm{CH}$ constants could certainly be obtained with the identification of the infrared rovibrational $\mathrm{X}-\mathrm{X}$ transition.

\subsection{Equilibrium constants and partition function}

\subsubsection{Equilibrium constants}

In Table 13 we present equilibrium molecular constants (in $\mathrm{cm}^{-1}$ ) for the four lowest doublet electronic states of ${ }^{12} \mathrm{CH}$, including the $a^{4} \Sigma^{-}$state for which the constants are taken from Kalemos et al. (1999) and Lie et al. (1973). These constants were used to compute the potential curves and the transition-moment matrix elements (see Sect. 2). Moreover, our final results yield 
Table 10. Constants (in $\mathrm{cm}^{-1}$ ) for the $\mathrm{A}^{2} \Delta$ state of ${ }^{13} \mathrm{CH}$.

\begin{tabular}{lllll}
\hline \hline Constant & $v=0$ & $v=1$ & $v=2$ & $v=3$ \\
\hline$T_{v}$ & $23173.84500(200)$ & $25906.4648(33)$ & $28447.0001(50)$ & $30775.3828(78)$ \\
& $23173.84460(69)^{a}$ & $25906.4596(15)^{a}$ & $28446.9953(30)^{a}$ & $30775.3748(59)^{a}$ \\
$B_{v}$ & $14.492570(100)$ & $13.830140(110)$ & $13.11333(140)$ & $12.31697(34)$ \\
& $14.492358(41)^{a}$ & $13.830193(54)^{a}$ & $13.113259(88)^{a}$ & $12.31700(24)^{a}$ \\
$A_{v}$ & $-1.09930(270)$ & $-1.0741(33)$ & $-1.0312(38)$ & $-1.0000(68)$ \\
& $-1.09926(90)^{a}$ & $-1.0735(12)^{a}$ & $-1.0339(35)^{a}$ & $-0.9981(38)^{a}$ \\
$\gamma_{v} \times 10^{2}$ & $4.211(66)$ & $4.056(77)$ & $3.717(78)$ & $3.530(160)$ \\
& $4.184(24)^{a}$ & $3.999(28)^{a}$ & $3.783(48)^{a}$ & $3.470(53)^{a}$ \\
$D_{v} \times 10^{3}$ & $1.54753(74)$ & $1.58069(82)$ & $1.64999(87)$ & $1.7963(34)$ \\
& $1.54745(28)^{a}$ & $1.58442(54)^{a}$ & $1.65055(48)^{a}$ & $1.7972(22)^{a}$ \\
$H_{v} \times 10^{8}$ & $9.610(180)$ & $5.05(18)$ & 0.0 & 0.0 \\
& $9.664(65)^{a}$ & $6.92(20)^{a}$ & $0.0^{a}$ & $0.0^{a}$ \\
$L_{v} \times 10^{11}$ & $-2.61(14)$ & 0.0 & 0.0 & 0.0 \\
& $2.667(50)^{a}$ & $2.54(24)^{a}$ & $0.0^{a}$ & $0.0^{a}$ \\
$\gamma_{D v} \times 10^{5}$ & $-1.140(220)$ & $-1.610(270)$ & 0.0 & 0.0 \\
& $-0.907(75)^{a}$ & $-0.714(89)^{a}$ & $0.0^{a}$ & $0.0^{a}$ \\
$p_{v} \times 10^{7}$ & 0.0 & 0.0 & 0.0 & 0.0 \\
& $5.7(18)^{a}$ & $10.4(74)^{a}$ & $20.5^{a, b}$ & $27.5^{a, b}$ \\
$q_{v} \times 10^{8}$ & 0.0 & 0.0 & 0.0 & 0.0 \\
& $-2.84(41)^{a}$ & $-16.3(23)^{a}$ & $-32.4^{a, b}$ & $-47.3^{a, b}$ \\
\hline
\end{tabular}

Notes. Uncertainties in parentheses are one standard deviation in units of the last quoted digit. ${ }^{(a)}$ Constants derived by Zachwieja (1997). ${ }^{(b)}$ kept fixed in Zachwieja (1997).

Table 11. Constants (in $\mathrm{cm}^{-1}$ ) for the $\mathrm{B}^{2} \Sigma^{-}$state of ${ }^{13} \mathrm{CH}$.

\begin{tabular}{lll}
\hline \hline Constant & $v=0$ & $v=1$ \\
\hline$T_{v}$ & $25713.4438(29)$ & $27504.4876(40)$ \\
& $25713.4456(13)^{a}$ & $27504.4859(21)^{a}$ \\
$B_{v}$ & $12.56638(22)$ & $11.09913(67)$ \\
& $12.56652(11)^{a}$ & $11.09953(20)^{a}$ \\
$\gamma_{v} \times 10^{2}$ & $-2.700(74)$ & $-2.206(80)$ \\
& $-2.680(110)^{a}$ & $-2.260(110)^{a}$ \\
$D_{v} \times 10^{3}$ & $2.10830(400)$ & $3.0660(290)$ \\
& $2.10289(89)^{a}$ & $3.0621(35)^{a}$ \\
$H_{v} \times 10^{7}$ & $-3.540(270)$ & $-28.9(35)^{a}$ \\
& $-3.945(30)^{a}$ & $-29.57^{a, b}$ \\
$L_{v} \times 10^{10}$ & $-1.31(60)$ & 0.0 \\
& $0.0^{a}$ & $0.0^{a}$ \\
$\gamma_{D v} \times 10^{5}$ & $1.19(41)$ & 0.0 \\
& $0.0^{a}$ & $0.0^{a}$ \\
\hline
\end{tabular}

Notes. Uncertainties in parentheses are one standard deviation in units of the last quoted digit. ${ }^{(a)}$ Constants derived by Para (1996).

a dissociation energy for the $\mathrm{CH}$ molecule of $27960 \pm 10 \mathrm{~m}^{-1}$ $(=3.4666 \pm 0.0013 \mathrm{eV})$ in agreement with the work of Kumar et al. (1998).

\subsubsection{Partition function}

Using our calculated levels up to the dissociation energy limit, we compute the partition function $Q$ following Tatum (1966),

$Q(T)=\sum_{i=0}^{E_{i} \leq D_{0}^{0}} g_{i} \mathrm{e}^{-\frac{E_{i}}{k . T}}$,
Table 12. Constants (in $\mathrm{cm}^{-1}$ ) for the $\mathrm{C}^{2} \Sigma^{+}$state of ${ }^{13} \mathrm{CH}$.

\begin{tabular}{ll}
\hline \hline Constant & $v=0$ \\
\hline$T_{v}$ & $31791.8419(33)$ \\
& $31791.8329(31)^{(a)}$ \\
$B_{v}$ & $14.17064(20)$ \\
& $14.17132(35)^{(a)}$ \\
$\gamma_{v} \times 10^{2}$ & $4.001(80)$ \\
& $4.030(250)^{(a)}$ \\
$D_{v} \times 10^{3}$ & $1.5666(20)$ \\
& $1.5728(27)^{(a)}$ \\
$H_{v} \times 10^{8}$ & $4.49(53)$ \\
& $5.15(51)^{(a)}$ \\
$\gamma_{D v} \times 10^{5}$ & 0.0 \\
& $2.03^{a, b}$ \\
\hline
\end{tabular}

Notes. Uncertainties in parentheses are one standard deviation in units of the last quoted digit. ${ }^{(a)}$ Values from Li et al. (1999). ${ }^{(b)}$ Constants kept fixed in Bembenek et al. (1997).

where $T$ is the temperature, $g_{i}=2 J+1$ is the multiplicity of a single $\Lambda$-doubling rotational level of energy $E_{i}$, and $k$ is the Boltzmann constant. For the $X^{2} \Pi, A^{2} \Delta, B^{2} \Sigma^{-}$, and $C^{2} \Sigma^{+}$states we used the constants derived in this work. We also included the low-lying $a^{4} \Sigma^{-}$state with constants from Lie et al. (1973) and Kalemos et al. (1999), important for the accuracy of the partition function. Following the formula $\ln (Q)=\sum_{0}^{2} a_{i} \ln (T)^{i}$, the derived coefficients for our new partition function are $a_{0}=$ 11.00608809, $a_{1}=-2.68892131$ and $a_{2}=0.27091654$. This updated partition function differs from that of Sauval $\&$ Tatum (1984) by $6 \%$ at $T=4000 \mathrm{~K}$, and $2 \%$ at $6000 \mathrm{~K}$ (see Fig. 5).

A47, page 10 of 29 
Table 13. Equilibrium constants for ${ }^{12} \mathrm{CH}$.

\begin{tabular}{lccccc}
\hline \hline Constant & $\mathrm{X}^{2} \Pi$ & $a^{4} \Sigma^{-}-$ & $\mathrm{A}^{2} \Delta$ & $\mathrm{B}^{2} \Sigma^{-}-$ & $\mathrm{C}^{2} \Sigma^{+}$ \\
\hline$D_{\mathrm{e}}\left(\mathrm{cm}^{-1}\right)$ & 29374.0 & 23349.6 & 16210.26 & 4731.57 & 7549.36 \\
$D_{0}^{0}\left(\mathrm{~cm}^{-1}\right)$ & 27959.64 & & & & \\
$r_{\mathrm{e}}(\AA)$ & 1.11981 & 1.0892 & 1.10366 & 1.16370 & 1.12777 \\
\hline$T_{\mathrm{e}}$ & 0.0 & $6024.40^{a}$ & 23148.7375 & 24642.425 & 31809.6428 \\
$\omega_{\mathrm{e}}$ & 2860.9238 & $3090.9^{a}$ & 2923.3763 & 2255.07 & 2853.1724 \\
$\omega_{\mathrm{e}} x_{\mathrm{e}}$ & 64.58180 & $102.17^{a}$ & 90.2 & $223.2^{c}$ & 120.8564 \\
$\omega_{\mathrm{e}} y_{\mathrm{e}}$ & 0.407275 & & -0.1917 & & \\
$\omega_{\mathrm{e}} z_{\mathrm{e}}$ & -0.01980 & & -0.3892 & & \\
\hline$B_{\mathrm{e}}$ & 14.45924 & $15.364^{b}$ & 14.88536 & 13.3818 & 14.56066 \\
$\alpha_{\mathrm{e}}$ & 0.53502 & $0.553^{b}$ & -0.591798 & 1.4828 & 0.56653 \\
$\gamma_{\mathrm{e}}$ & 0.001993 & & -0.047110 & & -0.08659 \\
$\epsilon_{\mathrm{e}}$ & 0.000214 & & 0.00782 & & \\
\hline
\end{tabular}

Notes. ${ }^{(a)}$ Constants taken from Kalemos et al. (1999). ${ }^{(b)}$ Constants taken from Lie et al. (1973). ${ }^{(c)}$ Value fixed according to Lie et al. (1973).

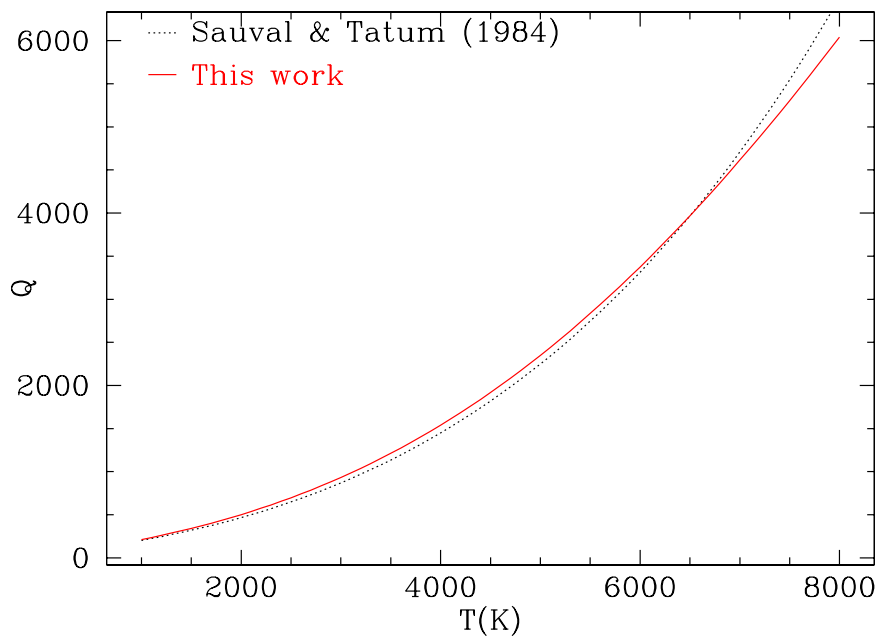

Fig. 5. Our new partition function compared to the work of Sauval \& Tatum (1984). The discrepancy is on average $3 \%$.

\subsection{Linelist format}

Our linelist includes the $\mathrm{A}-\mathrm{X}, \mathrm{B}-\mathrm{X}$, and $\mathrm{C}-\mathrm{X}$ electronic transitions up to the last observed vibrational levels (i.e. $v \leq 5$ for the $\mathrm{X}$ and A states, $v \leq 1$ for the $\mathrm{B}$ state, and $v \leq 2$ for the $\mathrm{C}$ state), with rotational levels up to the dissociation energy as listed in Table 13. Concerning the ${ }^{13} \mathrm{CH}$ linelists, for the vibrational levels that could not be observed but that exist for ${ }^{12} \mathrm{CH}$ (i.e. $X^{2} \Delta v=4$ and $5, A^{2} \Delta v=4$ and 5, and $\mathrm{C}^{2} \Sigma^{+} v=1$ and 2), the Born-Oppenheimer approximation from ${ }^{12} \mathrm{CH}$ has been used to determine the transitions applying the Jorgensen (1994) formulas (3), (4), and (5). The X-X ro-vibrational transitions up to dissociation are also included for both isotopologues.

The linelist is available on http://www.astro.ulb.ac. be/ spectrotools/, and will be made available through the VALD database (Kupka et al. 1999). An example of the default output format is presented in Table 14. The database offers various output formats and unit conversions. The $g f$ value is defined as in Larsson (1983),

$g f=\left(2 J^{\prime \prime}+1\right) \times f_{J^{\prime \prime} J^{\prime}}=\frac{m_{\mathrm{e}} \epsilon_{0} c}{2 \pi e^{2} v^{2}}\left(2 J^{\prime}+1\right) A_{J^{\prime \prime} J^{\prime}}$,

$f_{J^{\prime} J^{\prime \prime}}$ being the absorption oscillator strength and $v$ the line position in $\mathrm{cm}^{-1}$.
Additionally, in our final linelist, we have included radiative and predissociation broadening $\left(\Gamma_{\mathrm{rad}}\right)$, using the formula

$\Gamma_{\mathrm{rad}}=1 / \tau_{v^{\prime} J^{\prime}}^{\mathrm{rad}}+1 / \tau_{v^{\prime} J^{\prime}}^{\mathrm{predissoc}}$,

where $\tau^{\mathrm{rad}}$ is the radiative lifetime and $\tau^{\text {predissoc }}$ is the predissociation lifetime of the level in seconds. This broadening includes both the radiative lifetime and the predissociation lifetime as measured by Luque \& Crosley (1996a), Luque \& Crosley (1996b) and Brzozowski et al. (1976) for, respectively, the A, B, and $\mathrm{C}$ state.

\section{Conclusion}

We have compiled the most up-to-date and extensive list of the main $\mathrm{CH}$ transitions observed in stellar spectra (ro-vibrational, $\mathrm{A}-\mathrm{X}, \mathrm{B}-\mathrm{X}$, and $\mathrm{C}-\mathrm{X}$ ). This list includes line positions as well as oscillator strengths and line broadening (radiative + predissociation). The combination of laboratory measurements and astronomical observations also allows the molecular data to be improved for this molecule. We have demonstrated that carefully selected stellar spectra can significantly improve molecular data despite their relatively poor quality compared to laboratory experiments or the solar spectrum. Although we were able to identify many new levels and we were able to assemble a large quantity of laboratory data, all levels of the $\mathrm{CH}$ molecules have not been identified. Therefore, the linelist we provide here is not complete, but is the most accurate exisiting for stellar spectroscopists. Other electronic transitions have been observed in some astrophysical contexts in the far UV (D-X, E-X, and F-X; Watson 2001; Sheffer \& Federman 2007). Laboratory data for these transitions can be found concerning the line positions and constants in Li \& Lee (1999) and Herzberg \& Johns (1969) for the D state, Watson (2001) and Sheffer \& Federman (2007) for E and F, while Kalemos et al. (1999) provide theoretical values for all of them. The corresponding transition moments have also been calculated in van Dishoeck (1987). The D and F states are also known to be highly predissociative (Herzberg \& Johns 1969). Predissociation lifetimes for these states can be found in Metropoulos \& Mavridis (2000). However, we did not include these transitions in our linelists because they are expected to be of minor importance for stellar spectra. We also highlight the fact that predissociation is not only known to exist in $\mathrm{CH}$, but also in other molecules of astrophysical interest $\left(\mathrm{NH}, \mathrm{H}_{2} \mathrm{O}\right.$, etc.) (see Kato \& Baba 1995). 


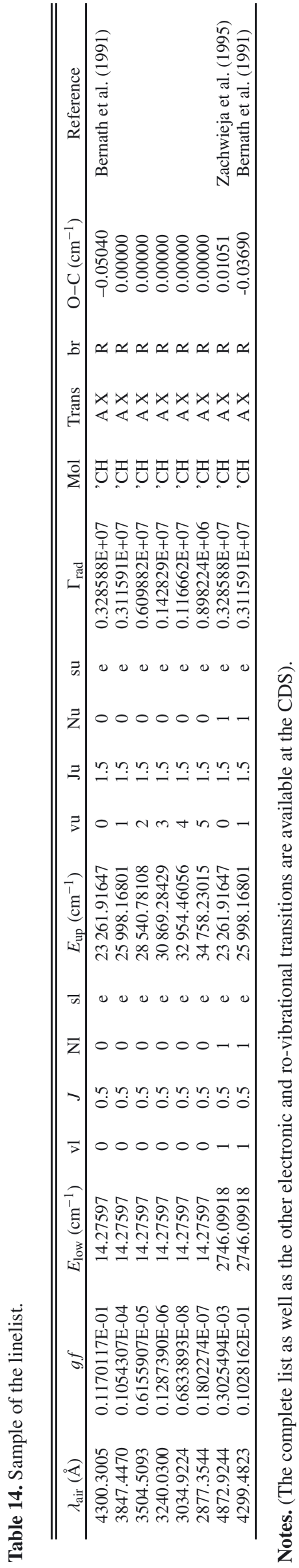

Acknowledgements. T.M., S.v.E. and A.J. are supported in part by an Action de Recherche Concertée from the Direction générale de l'enseignement non obligatoire et de la Recherche Scientifique - Direction de la Recherche Scientifique - Communauté Française de Belgique and by the F.R.S.-FNRS FRFC grant 2.4533.09. Some support was also provided by the NASA laboratory astrophysics program. N.C. acknowledges support by Sonderforschungsbereich SFB 881 "The Milky Way System" (subprojects A2, A4, and A5) of the German Research Foundation(DFG). This work has used data from ESO program ID 69.D-0063(A).

\section{Appendix A: Atlas of predissociation lines}

\section{A.1. Predissociation lines in astronomical spectra}

In the course of a study of carbon-enhanced metal-poor (CEMP) stars (Christlieb et al. 2002; Masseron 2006; Masseron et al. 2006, 2010, 2012), we came across wide and shallow lines spread in the wavelength ranges $\lambda 3660-3770 \AA$ and 13920-4130 A (Fig. 3). Realising that these ranges matched those of the $\mathrm{B}-\mathrm{X}$ system of the $\mathrm{CH}$ molecule, it soon became clear that these wide and shallow lines are in fact predissociation lines. It prompted the present work on the $\mathrm{CH}$ molecular linelist.

In molecules, different types of transitions may occur. If the energy provided to the molecule is higher than that needed to separate the atomic components, then dissociation occurs and no lines are formed. If both the upper and lower states of the transition are below the dissociation limit, the classical quantized transition occurs and a line forms. However, if a bound transition involves a level having a nearby unbound level, an internal conversion may occur, leaving the transition in the so-called predissociation state. Because the unbound level has a finite lifetime associated with the molecular dissociation, the lines associated with such transitions appear broadened beyond the natural broadening (Herzberg 1950) once the predissociation lifetime becomes shorter than the radiative lifetime. There are various situations leading to predissociation. The unbound level can be of the same or a different electronic state, but certain selection rules must be fulfilled (see Herzberg 1950). Furthermore, the predissociation may be internal to a molecule but can also be induced by external factors (e.g. magnetic fields).

For the $\mathrm{CH}$ molecule, predissociation is expected for the $\mathrm{A}$, B, C, and D states. Predissociation was first observed in the laboratory by Shidei (1936) and confirmed by Herzberg \& Johns (1969), and Ubachs et al. (1986) and studied theoretically in more detail by Elander \& Smith (1973), Brooks \& Smith (1974), Elander et al. (1979), and van Dishoeck (1987). For the A state, Brzozowski et al. (1976) noticed that the line structure disappears for energies below the dissociation limit, but reappears again at higher energies. They attribute this predissociation to perturbation of the $\mathrm{X}^{2} \Pi$ ground state and from the $\mathrm{B}^{2} \Sigma^{-}$state. Brzozowski et al. (1976) and Elander et al. (1979) show that the B-state has a potential barrier above the dissociation limit (see Fig. A.1), so that its predissociation occurs by tunneling through the barrier by quasibound levels. Although a similar bump in the potential curve of the $\mathrm{C}$ state is observed, Brzozowski et al. (1976) and Elander \& Smith (1973) first suspected the $a^{4} \Sigma$ to be responsible for the perturbation of the $\mathrm{C}$ state leading to its predissociation. Nevertheless, more recent calculations of the C state by van Dishoeck (1987) and observations by Ubachs et al. (1986) show that the predissociation of the C state is instead due to interaction with the B state. Finally, van Dishoeck (1987) also predicted the D state to be entirely predissociated.

Although the predissociation phenomenon has been extensively observed in the laboratory, predissociation lines have 
Table A.1. Stellar parameters of the stars presented in the atlas.

\begin{tabular}{lccccc}
\hline \hline Star & $T_{\text {eff }}$ & $\log (g)$ & {$[\mathrm{Fe} / \mathrm{H}]$} & {$[\mathrm{C} / \mathrm{Fe}]$} & Reference \\
\hline HD 187861 & 4600 & 1.7 & -2.4 & 2.1 & Masseron et al. (2010) \\
CS 22942-019 & 5100 & 2.5 & -2.5 & 2.2 & Masseron et al. (2010) \\
HE 1419-1324 & 5600 & 3.2 & -2.1 & 1.2 & Masseron et al. (2010) \\
Arcturus & 4300 & 1.5 & -0.5 & 0.0 & Decin et al. (2003) \\
Sun & 5777 & 4.44 & 0.0 & 0.0 & \\
\hline
\end{tabular}

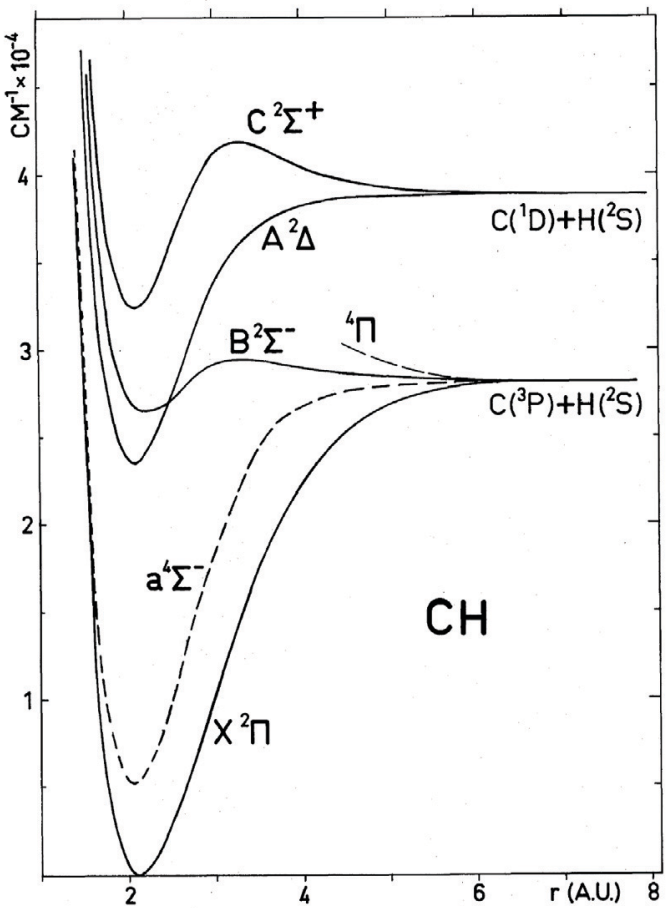

Fig. A.1. Potential curves of the lowest excited electronic states in $\mathrm{CH}$ (extracted from Brzozowski et al. 1976).

rarely been identified in astronomical objects: $\mathrm{NH}_{3}$ and $\mathrm{NH}_{2}$ predissociation lines have been observed in Halley's comet (Fink et al. 1992). Predissociation lines are often discussed in relation with diffuse interstellar bands (DIBs; see Herbig 1975, 1995; Fulara \& Krełowski 2000). Hubble Space Telescope observations of Watson (2001) assign the $\sim 1370 \AA$ DIBs to the $\mathrm{CH}$ molecule. Later on, Sheffer \& Federman (2007) confirmed this finding and extended it to the 1271, 1549, and $1694 \AA$ A DIBs. Carbon-rich stars present a large number of molecular features, and notably of $\mathrm{CH}$, including predissociation lines. Because broadening in stellar spectra is large compared to laboratory spectra, only B-X predissociation lines are detectable. However, the thermodynamical conditions in their atmospheres allow us to observe a large number of those lines that we list in the following atlas.

\section{A.2. Atlas}

We present here an atlas of predissociation lines in carbonrich stars (see Table A.1 for the stellar sample), the Sun, and Arcturus. The catalog (Figs. A.3-A.10) clearly reveals the peculiar shapes that may be encountered in spectra, especially in

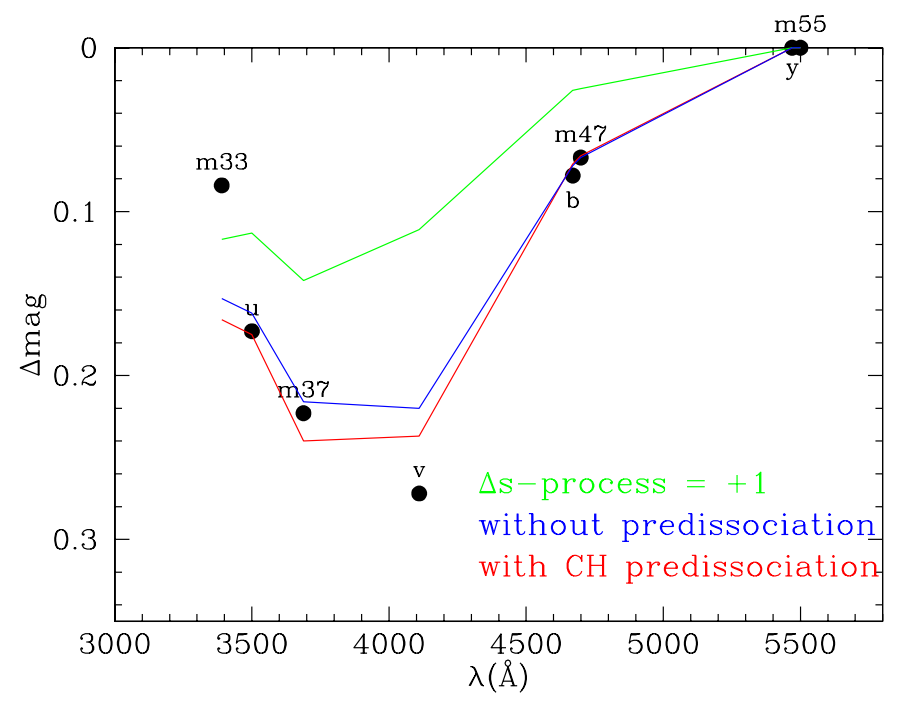

Fig. A.2. Drop in magnitudes in the blue-yellow spectra of the barium star $\zeta$ Cap compared to the normal giant o Uma due to blanketing by heavy elements and by $\mathrm{CH}$ and $\mathrm{CN}$. The black dots correspond to different photometric bands, as taken from Bond \& Neff (1969), and the continuous lines correspond to the synthetic spectra with s-process elements increased by +1 dex (green line) and with $\mathrm{CH}$ added with (red line) or without (blue line) predissociation lines. While similar atmospheric parameters were used, carbon and s-process element overabundances of 0.5 dex and 1 dex were adopted, respectively.

carbon-rich stars where they are the most conspicuous, but also in normal stars like the Sun.

\section{A.3. The Bond-Neff depression}

In this section we evaluate the impact of the $\mathrm{CH}$ bands on lowresolution spectra and photometry, especially in the context of the Bond-Neff depression (Bond \& Neff 1969) observed in barium stars (Bidelman \& Keenan 1951), which are G-K giants enriched in carbon and heavy elements predominantly produced in the s-process nucleosynthesis (see Käppeler et al. 2011, for a recent review).

Although the Bond-Neff depression was first assigned to $\mathrm{CN}$ and $\mathrm{CH}$ molecules, the depression was not satisfactorily accounted for with the old linelists. McWilliam \& Smith (1984) therefore suggested a contribution from blanketing by heavy elements. By computing synthetic spectra for two among the barium stars originally considered by Bond \& Neff (1969), we show in Fig. A. 2 that there is now a very good agreement between predicted and observed colours, thanks to our complete molecular and atomic linelists. As demonstrated by this figure, both heavyelement and $\mathrm{CH}$ blanketing (including $\mathrm{CH}$-predissociation lines) are necessary to reproduce the Bond-Neff depression. 

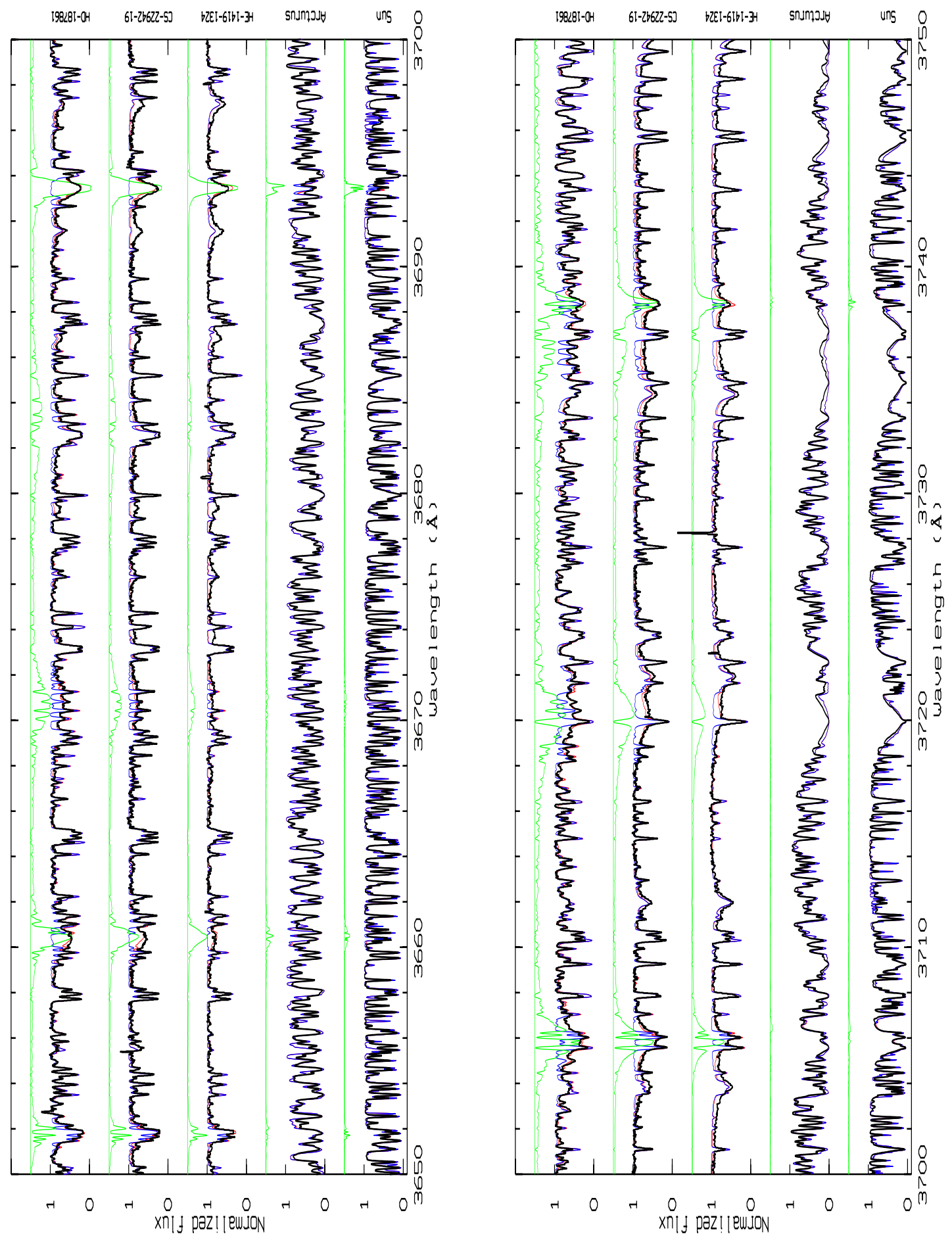

Fig. A.3. Atlas of predissociation lines for a sample of stars. The black line shows the observations while the red lines shows the synthetic fit with all atomic and molecular lines included, the blue line shows the synthetic fit without $\mathrm{CH}$ predissociation lines and the green line shows the contribution of the $\mathrm{CH}$ predissociation lines alone. We note that the continuum has been arbitrarily placed at 1.5 for the synthetic fit. See Table A.1 for a list of the basic properties of the displayed stars. 
T. Masseron et al.: $\mathrm{CH}$ in stellar atmospheres: an extensive linelist
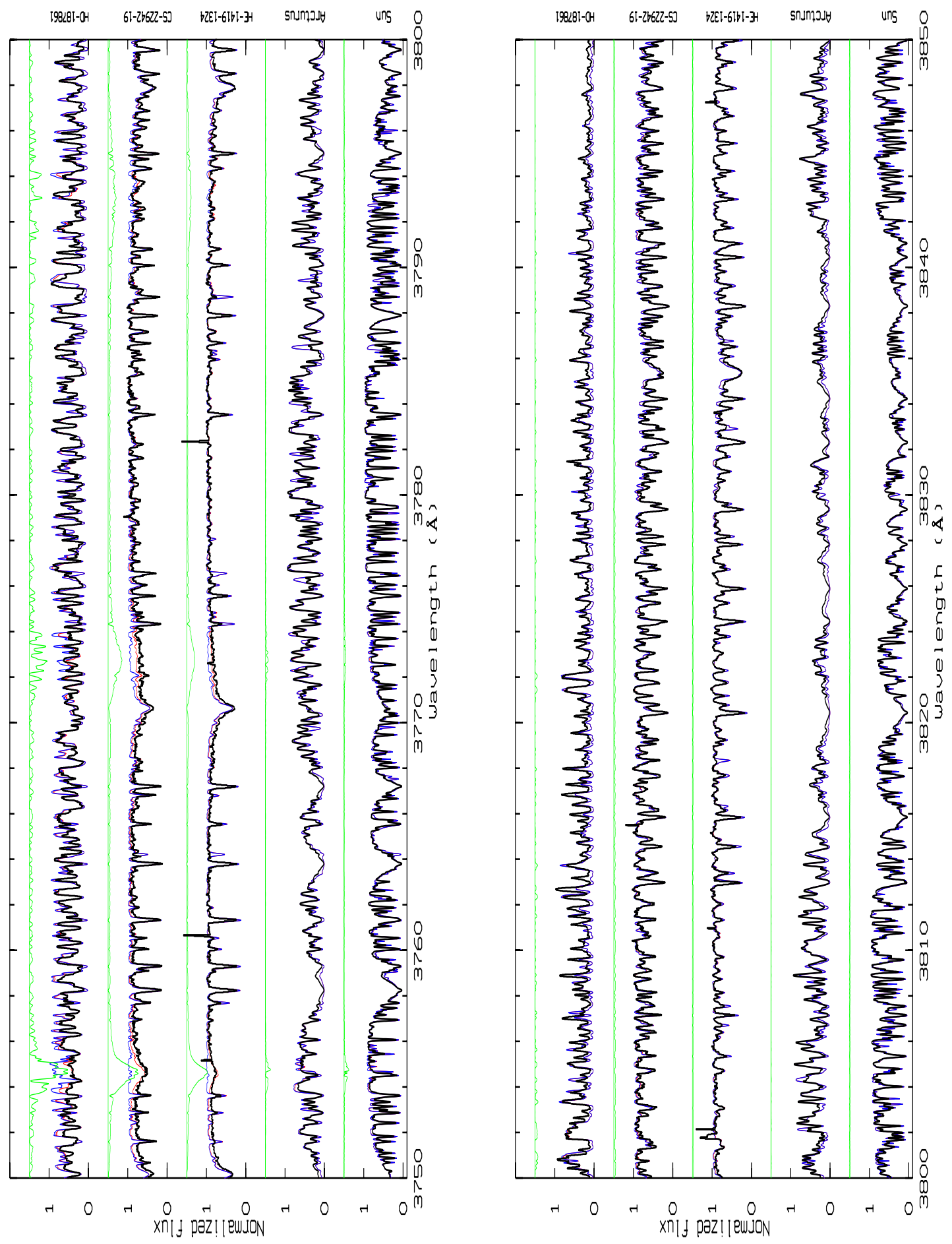

Fig. A.3. continued. 
A\&A 571, A47 (2014)
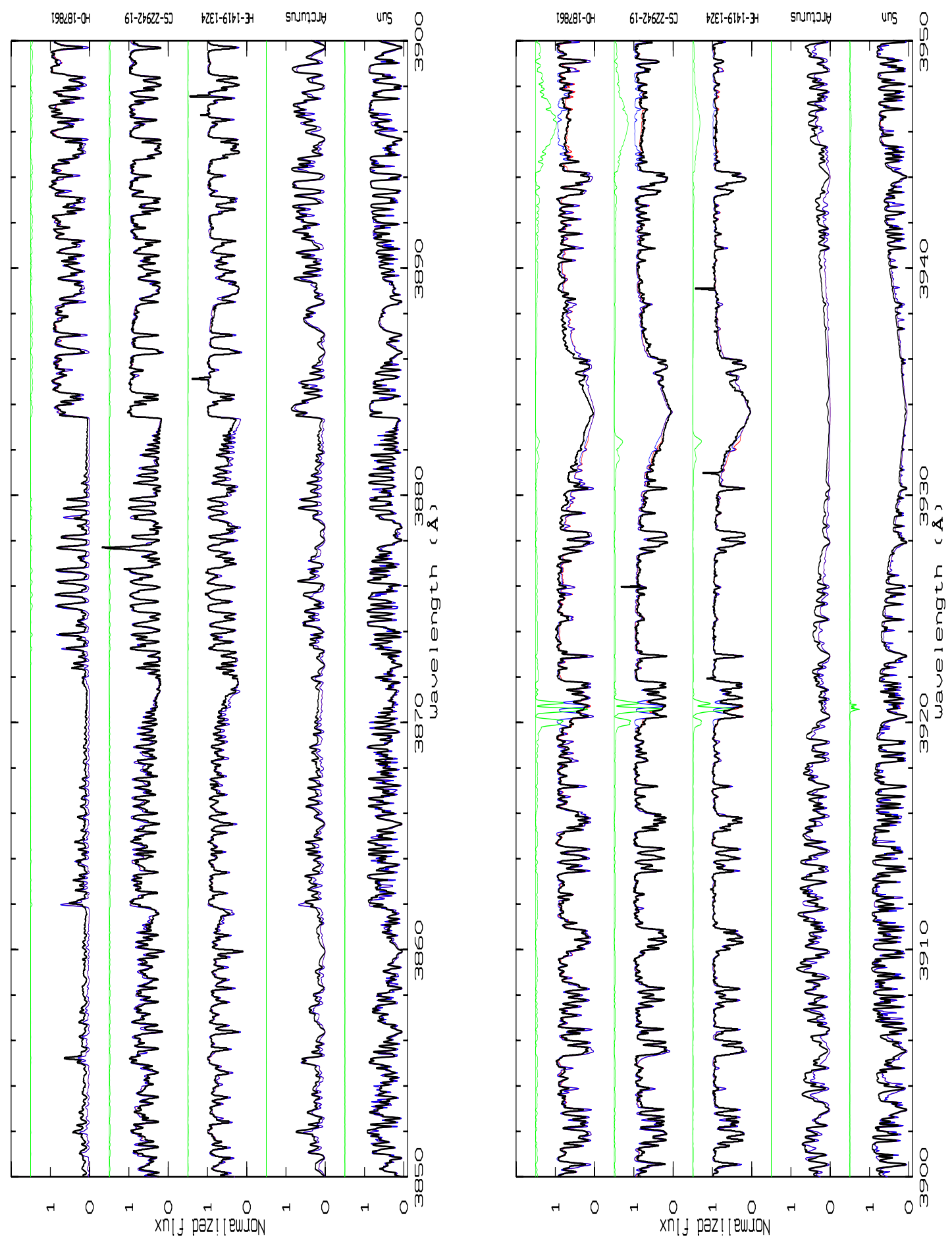

Fig. A.3. continued. 
T. Masseron et al.: $\mathrm{CH}$ in stellar atmospheres: an extensive linelist
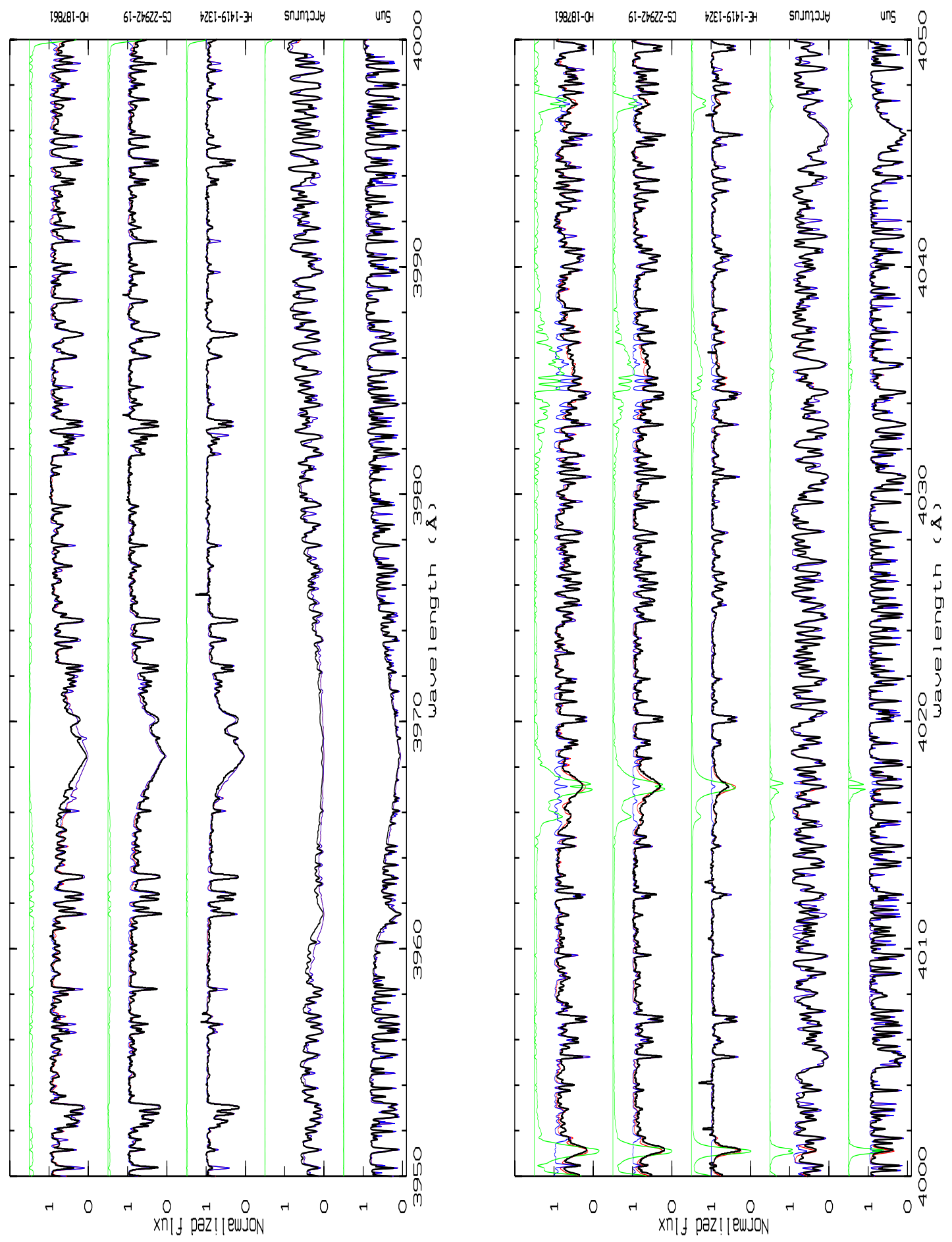

Fig. A.3. continued. 
A\&A 571, A47 (2014)
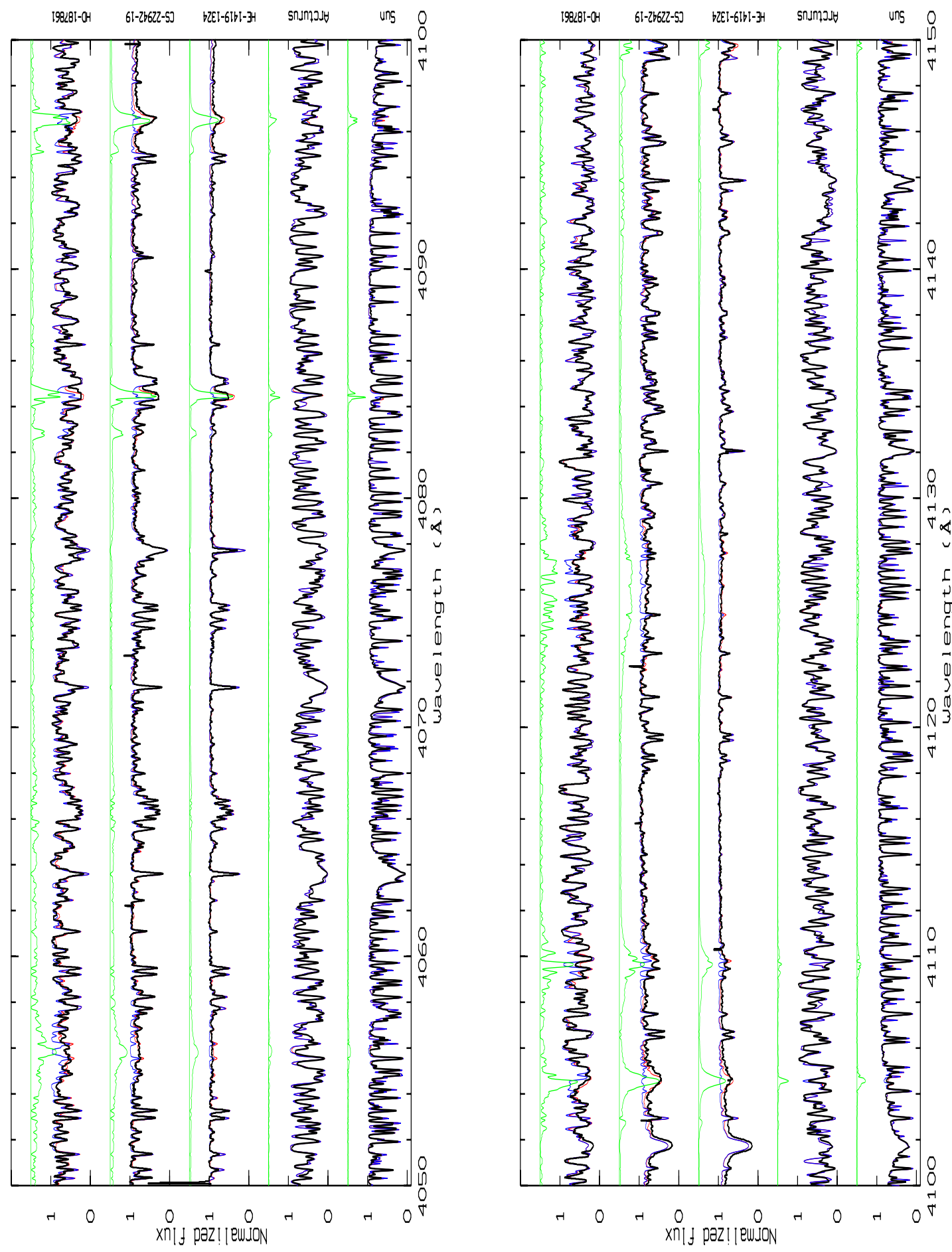

Fig. A.3. continued. 
T. Masseron et al.: $\mathrm{CH}$ in stellar atmospheres: an extensive linelist
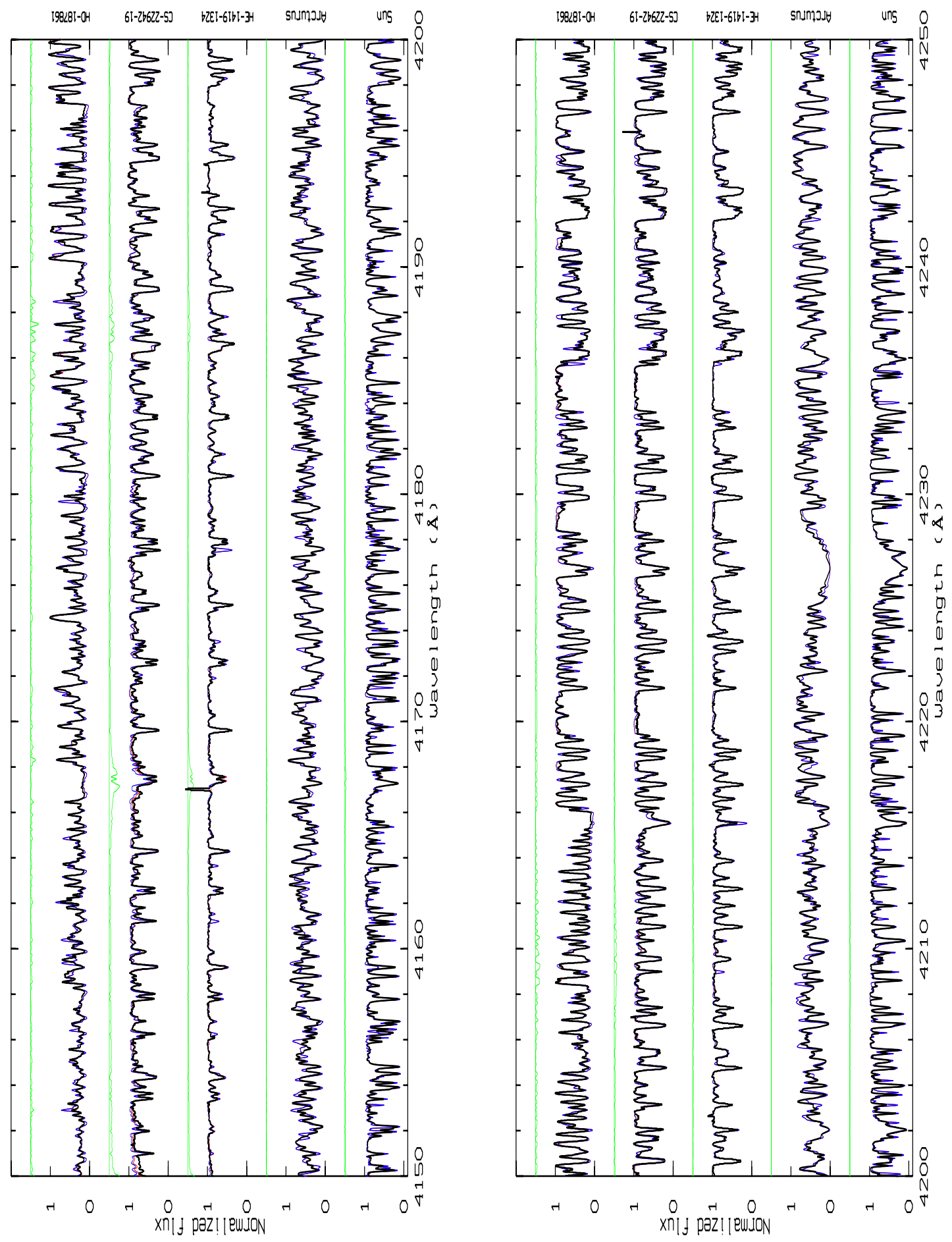

Fig. A.3. continued. 
A\&A 571, A47 (2014)
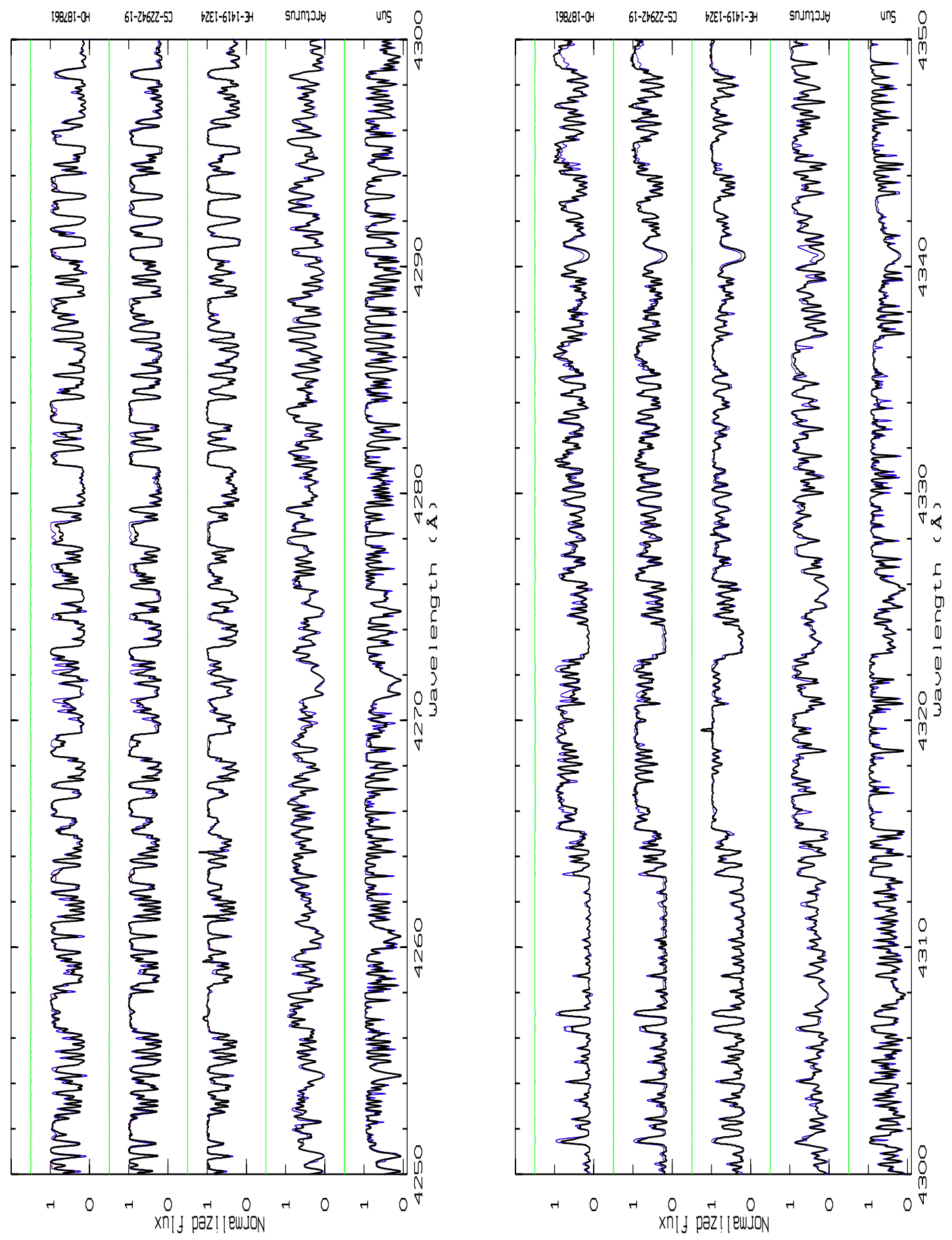

Fig. A.3. continued. 
T. Masseron et al.: $\mathrm{CH}$ in stellar atmospheres: an extensive linelist
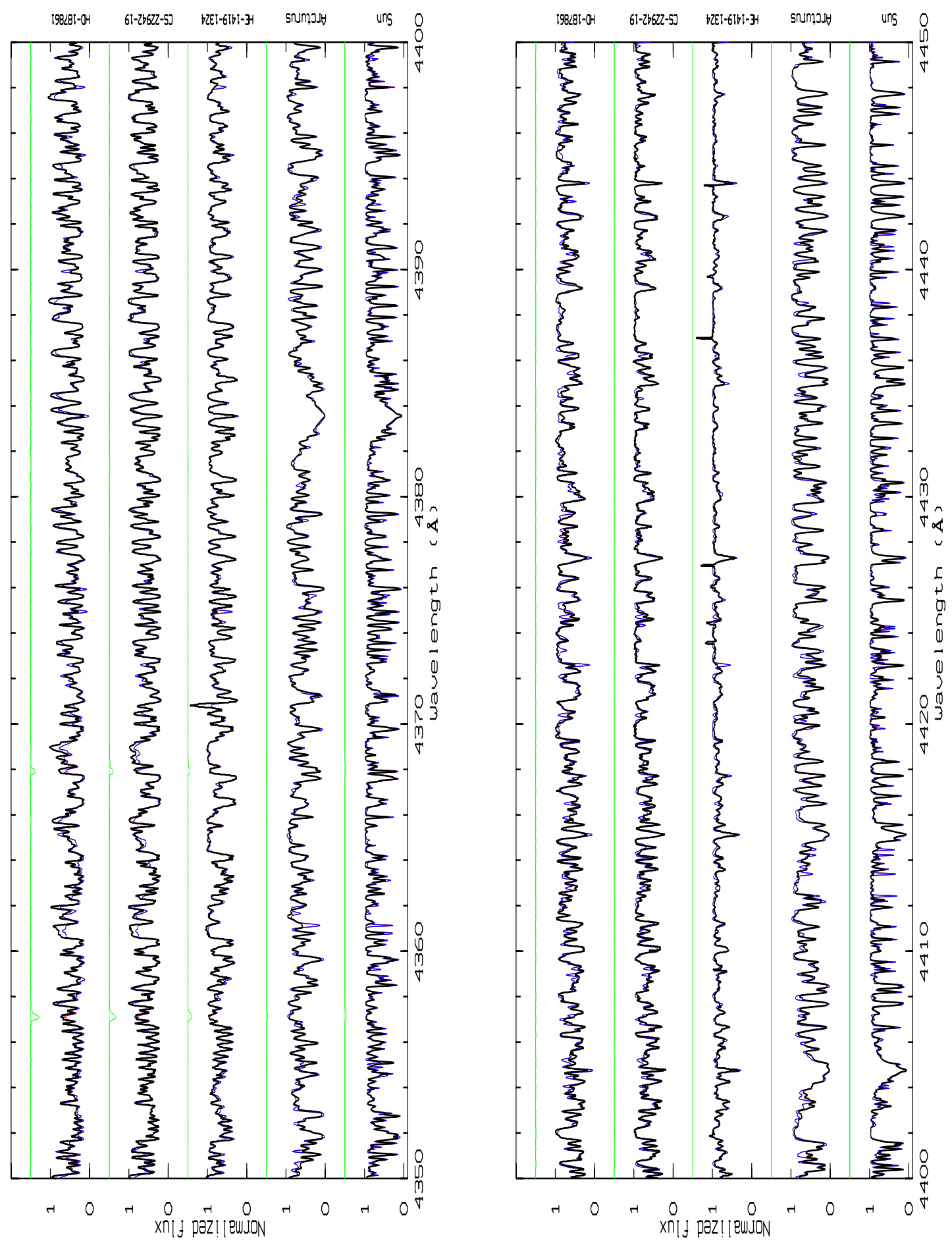

Fig. A.3. continued. 
Table A.2. Vacuum wavenumbers $\left(\mathrm{cm}^{-1}\right)$ of clean CH A-X transitions in CS22942-019 used for the calculation of the constants.

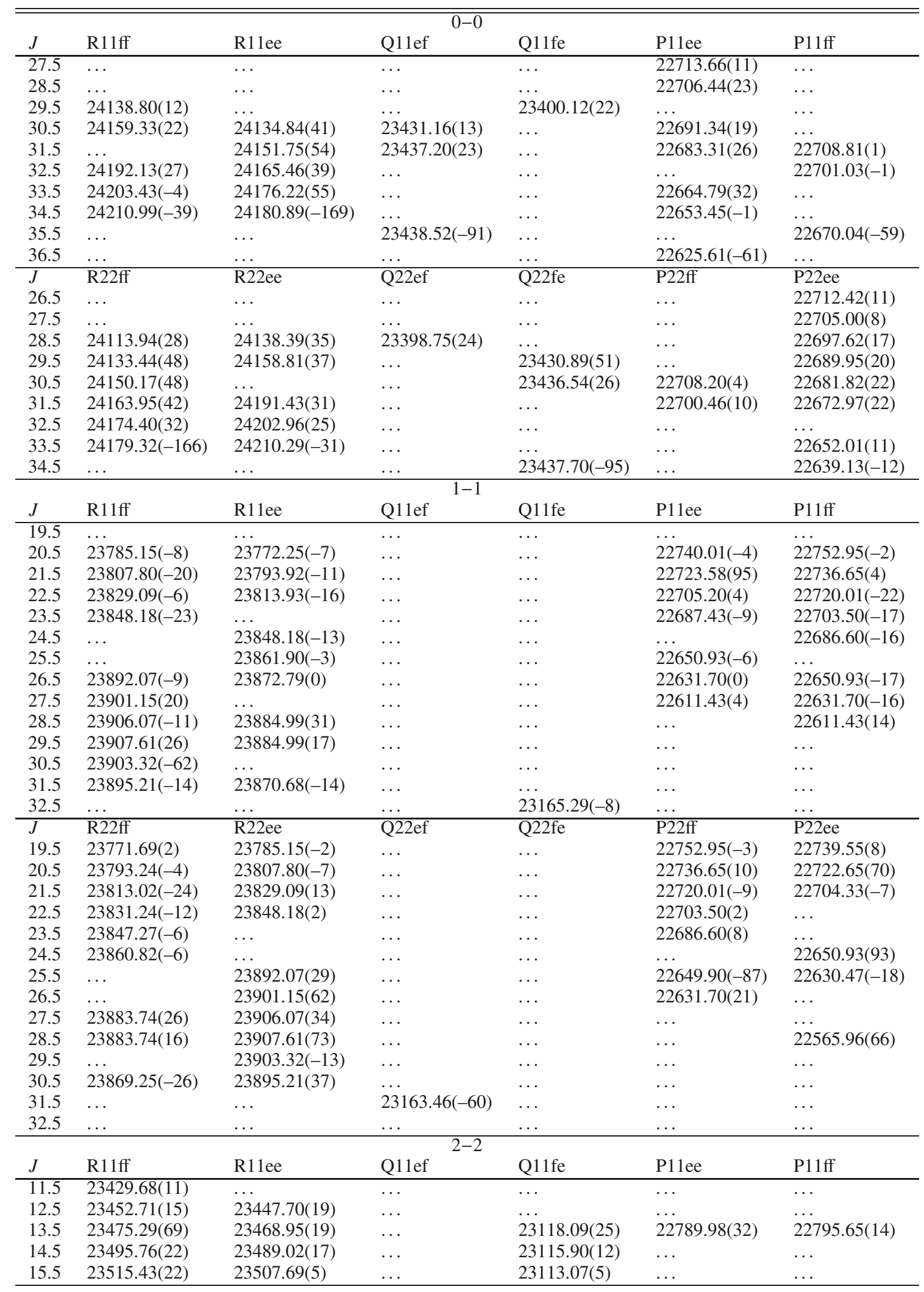

Notes. The numbers in parentheses are the observed-calculated value. 
T. Masseron et al.: $\mathrm{CH}$ in stellar atmospheres: an extensive linelist

Table A.2. continued.

\begin{tabular}{|c|c|c|c|c|c|c|}
\hline 16.5 & 23533.64(20) & $\ldots$ & $23118.09(17)$ & $23109.49(6)$ & $22714.95(14)$ & $222723.58(28)$ \\
\hline 17.5 & $23550.11(8)$ & $\ldots$ & $23114.57(27)$ & $23104.74(-12)$ & $22689.33(0)$ & $22699.07(30)$ \\
\hline 18.5 & $\ldots$ & $23554.16(-17)$ & $23109.49(-5)$ & $23098.97(-16)$ & $22663.25(-14)$ & $22673.89(8)$ \\
\hline 19.5 & $23577.21(-11)$ & & $23103.51(5)$ & & $22636.67(-18)$ & $22648.31(5)$ \\
\hline 20.5 & $23587.28(-20)$ & $23574.99(-7)$ & $23095.66(-15)$ & $23083.13(-26)$ & $\ldots$ & $22621.92(-4)$ \\
\hline 21.5 & $\ldots$ & $23581.27(-16)$ & $23086.12(-22)$ & $23072.74(-14)$ & $\ldots$ & $22594.57(-10)$ \\
\hline 22.5 & $\ldots$ & $23584.38(-28)$ & $23074.50(-21)$ & & $22551.50(-17)$ & $\ldots$ \\
\hline 23.5 & $\ldots$ & $23584.38(6)$ & $23060.18(-41)$ & $23044.82(-23)$ & $22520.41(-20)$ & $\ldots$ \\
\hline 24.5 & $\ldots$ & $\ldots$ & $\ldots$ & $\ldots$ & $22487.54(-16)$ & $22503.99(-29)$ \\
\hline 25.5 & $\ldots$ & $23570.98(11)$ & $23023.01(-10)$ & $23005.42(-7)$ & $\ldots$ & $22469.89(-26)$ \\
\hline 26.5 & $23574.99(-21)$ & ... & $22998.70(-2)$ & $\ldots$ & $22414.48(-19)$ & $22433.24(-9)$ \\
\hline 27.5 & $23555.88(5)$ & $\ldots$ & $\ldots$ & $\ldots$ & $\ldots$ & $22393.04(-22)$ \\
\hline 28.5 & $\ldots$ & $23509.18(35)$ & $\ldots$ & $\ldots$ & $22329.17(55)$ & $22350.69(137)$ \\
\hline 29.5 & $\cdots$ & $\ldots$ & $\cdots$ & $\cdots$ & $22279.51(42)$ & $22300.93(15)$ \\
\hline 30.5 & $\cdots$ & $\cdots$ & $\cdots$ & $\cdots$ & $\ldots$ & $22246.69(-12)$ \\
\hline 31.5 & $\ldots$ & $\ldots$ & $\ldots$ & $\ldots$ & $22162.46(-36)$ & $22185.77(-66)$ \\
\hline$J$ & R22ff & R22ee & Q22ef & Q22fe & P22ff & P22ee \\
\hline 10.5 & $\ldots$ & $23430.28(-19)$ & $\ldots$ & $\ldots$ & $\ldots$ & $\ldots$ \\
\hline 11.5 & $23447.70(-20)$ & $23453.42(11)$ & $\ldots$ & $\ldots$ & $\ldots$ & $\ldots$ \\
\hline 12.5 & $23468.95(-3)$ & $23475.29(7)$ & $23118.09(-2)$ & $\ldots$ & $22796.27(5)$ & $22789.98(0)$ \\
\hline 13.5 & $23489.02(10)$ & $23495.76(-28)$ & $23115.90(0)$ & $\ldots$ & $\ldots$ & $\ldots$ \\
\hline 14.5 & $23507.69(10)$ & $23515.43(-18)$ & 23113.07(6) & & & \\
\hline 15.5 & $\ldots$ & $23533.64(-10)$ & $23109.49(20)$ & $23118.09(-16)$ & $22723.58(-10)$ & $22714.95(24)$ \\
\hline 16.5 & $\ldots$ & $23550.11(-14)$ & 23104.74(13) & $23114.57(2)$ & $22699.07(1)$ & $22689.33(21)$ \\
\hline 17.5 & $23553.94(-1)$ & & 23098.97(19) & $23109.49(-23)$ & $22673.53(-49)$ & $22663.25(17)$ \\
\hline 18.5 & $\ldots$ & $23577.21(-19)$ & $\ldots$ & $23103.51(-6)$ & $22648.31(-9)$ & $22636.52(8)$ \\
\hline 19.5 & $23574.43(-8)$ & $23587.28(-23)$ & $23082.71(-16)$ & $23095.66(-20)$ & $22621.92(-11)$ & $22609.03(0)$ \\
\hline 20.5 & $23580.82(1)$ & $\ldots$ & $23072.16(-13)$ & $23086.12(-22)$ & $22594.57(-12)$ & \\
\hline 21.5 & $23583.61(-38)$ & $\ldots$ & $23059.28(-28)$ & $23074.50(-17)$ & $\ldots$ & $22550.79(-24)$ \\
\hline 22.5 & 23583.61(1) & $\ldots$ & $\ldots$ & $23060.18(-32)$ & $\ldots$ & $22519.70(-20)$ \\
\hline 23.5 & $\ldots$ & $\begin{array}{l}\cdots \\
\ldots\end{array}$ & $\cdots$ & $\ldots$ & $22503.99(-18)$ & $22486.62(-31)$ \\
\hline 24.5 & $23569.98(-7)$ & & 23004.68(1) & 23023.01(4) & $22469.89(-13)$ & \\
\hline 25.5 & $23556.27(58)$ & $23574.99(-5)$ & $\ldots$ & $22998.70(14)$ & $22433.24(6)$ & $22413.72(-10)$ \\
\hline 26.5 & $\ldots$ & $23555.88(21)$ & $\ldots$ & $\ldots$ & $22393.04(-5)$ & $\ldots$ \\
\hline 27.5 & $\ldots$ & $\ldots$ & $\ldots$ & $\ldots$ & $22350.69(155)$ & $22327.83(10)$ \\
\hline 28.5 & $\ldots$ & $\ldots$ & $\ldots$ & $\ldots$ & $22300.93(33)$ & $22278.17(0)$ \\
\hline 29.5 & $\ldots$ & $\ldots$ & $\ldots$ & $\ldots$ & $22246.69(6)$ & \\
\hline 30.5 & $\ldots$ & $\ldots$ & $\ldots$ & $\ldots$ & $22185.77(-50)$ & $22161.57(-31)$ \\
\hline \multirow[t]{2}{*}{31.5} & $\ldots$ & $\ldots$ & $\ldots$ & $\ldots$ & $\ldots$ & $\ldots$ \\
\hline & & & $3-3$ & & & \\
\hline$J$ & R11ff & R11ee & Q11ef & Q11fe & P11ee & P11ff \\
\hline 11.5 & $\ldots$ & $\ldots$ & $\ldots$ & $\ldots$ & & $\ldots$ \\
\hline 12.5 & $\ldots$ & $\ldots$ & $\ldots$ & $\ldots$ & 22638.01(19) & $\ldots$ \\
\hline 13.5 & $\ldots$ & $\ldots$ & $\ldots$ & $\ldots$ & $22606.47(29)$ & $\ldots$ \\
\hline 14.5 & $\ldots$ & $\ldots$ & $\ldots$ & $22900.34(9)$ & $22573.75(17)$ & $\ldots$ \\
\hline 15.5 & $\ldots$ & $\ldots$ & $\ldots$ & $22886.66(2)$ & $22540.01(14)$ & $22547.33(20)$ \\
\hline 16.5 & $\ldots$ & $\ldots$ & $22879.38(21)$ & $\ldots$ & $\ldots$ & $\ldots$ \\
\hline 17.5 & $\ldots$ & $\ldots$ & $\ldots$ & $22853.02(-15)$ & $22468.28(-9)$ & $\ldots$ \\
\hline 18.5 & $\ldots$ & $\ldots$ & $22842.73(2)$ & $22832.61(-11)$ & $22429.92(-22)$ & $22440.19(7)$ \\
\hline 19.5 & $\ldots$ & $\ldots$ & & & $\ldots$ & $22400.67(-14)$ \\
\hline 20.5 & $\ldots$ & $\ldots$ & $22794.19(-29)$ & $22782.35(-22)$ & $22346.89(-32)$ & $22358.99(-14)$ \\
\hline 21.5 & $\ldots$ & $\ldots$ & $22764.61(-20)$ & $22751.66(-25)$ & & $22314.37(-29)$ \\
\hline 22.5 & $\ldots$ & $\ldots$ & $22730.50(-13)$ & $22716.55(-18)$ & $22252.73(-30)$ & $22266.71(-21)$ \\
\hline 23.5 & & $\ldots$ & $\ldots$ & $\ldots$ & $22200.30(-12)$ & $22215.10(-22)$ \\
\hline 24.5 & $23141.75(17)$ & $\ldots$ & & & 22143.36(9) & $22159.16(1)$ \\
\hline 25.5 & $\ldots$ & 23079.67(19) & $22593.60(23)$ & $22576.86(37)$ & $\ldots$ & $\ldots$ \\
\hline 26.5 & $\ldots$ & $\ldots$ & 22532.79(8) & & $\ldots$ & $\ldots$ \\
\hline 27.5 & $\ldots$ & $\ldots$ & $22461.62(-91)$ & $22443.41(-27)$ & $\ldots$ & $\ldots$ \\
\hline
\end{tabular}


Table A.2. continued.

\begin{tabular}{|c|c|c|c|c|c|c|}
\hline $\bar{J}$ & $\overline{\mathrm{R} 22 \mathrm{ff}}$ & R22ee & Q22ef & Q22fe & $\bar{P}$ P22ff & P22ee \\
\hline 11.5 & $\ldots$ & $\ldots$ & $\ldots$ & $\ldots$ & $\ldots$ & $22638.26(-4)$ \\
\hline 12.5 & $\ldots$ & $\ldots$ & $\ldots$ & $\ldots$ & $22612.51(1)$ & $22606.47(-3)$ \\
\hline 13.5 & $\ldots$ & $\ldots$ & $22900.34(-2)$ & $\ldots$ & $\ldots$ & $22573.75(0)$ \\
\hline 14.5 & $\ldots$ & $\ldots$ & $22886.66(5)$ & & $22547.53(-7)$ & $22540.01(11)$ \\
\hline 15.5 & $\ldots$ & $\ldots$ & $\ldots$ & $22879.38(-10)$ & $\ldots$ & $\ldots$ \\
\hline 16.5 & $\ldots$ & $\ldots$ & $22853.02(13)$ & & & $22468.28(13)$ \\
\hline 17.5 & $\ldots$ & $\ldots$ & $22832.61(27)$ & $22842.73(-11)$ & $22440.19(-11)$ & 22429.92(12) \\
\hline 18.5 & $\ldots$ & $\ldots$ & $\ldots$ & $\ldots$ & $22400.67(-23)$ & $\ldots$ \\
\hline 19.5 & $\ldots$ & $\ldots$ & $22781.88(-10)$ & $22794.19(-27)$ & $22358.99(-16)$ & $22346.54(-13)$ \\
\hline 20.5 & $\ldots$ & $\ldots$ & $22751.24(2)$ & $22764.61(-10)$ & $22314.37(-24)$ & $\ldots$ \\
\hline 21.5 & $\ldots$ & $\ldots$ & $22715.88(-9)$ & $22730.50(3)$ & $22266.71(-9)$ & $22252.19(-12)$ \\
\hline 22.5 & $\ldots$ & $\ldots$ & $\ldots$ & $\ldots$ & $22215.10(-3)$ & $22199.61(-1)$ \\
\hline 23.5 & $\cdots$ & $23141.75(49)$ & $\cdots$ & & $22159.16(25)$ & $22142.38(0)$ \\
\hline 24.5 & $23078.71(27)$ & $\ldots$ & $22576.05(56)$ & $22593.60(57)$ & $\ldots$ & $\ldots$ \\
\hline 25.5 & $\ldots$ & $\ldots$ & $\ldots$ & $22532.79(47)$ & $\ldots$ & $\ldots$ \\
\hline 26.5 & $\ldots$ & $\ldots$ & $\ldots$ & $22461.62(-47)$ & $\ldots$ & $\ldots$ \\
\hline 27.5 & $\ldots$ & $\ldots$ & $\ldots$ & $\ldots$ & $\ldots$ & $\ldots$ \\
\hline & & & $4-4$ & & & \\
\hline$J$ & $\mathrm{R} 11 \mathrm{ff}$ & R11ee & Q11ef & Q11fe & P11ee & P11ff \\
\hline 2.5 & $22766.84(5)$ & $22766.84(18)$ & & & $\ldots$ & $\ldots$ \\
\hline 3.5 & $\ldots$ & $\ldots$ & $22694.84(-16)$ & $22694.84(15)$ & $\ldots$ & $\ldots$ \\
\hline 4.5 & $\ldots$ & $\ldots$ & $\ldots$ & $\ldots$ & $\ldots$ & $\ldots$ \\
\hline 5.5 & $\ldots$ & $\ldots$ & $22684.18(5)$ & $\ldots$ & $22569.68(8)$ & $\ldots$ \\
\hline 6.5 & $\ldots$ & $\ldots$ & $\ldots$ & $\ldots$ & $\ldots$ & $\ldots$ \\
\hline 7.5 & $\ldots$ & $\ldots$ & $22666.75(-13)$ & $22665.00(-21)$ & $\ldots$ & $22509.21(-5)$ \\
\hline 8.5 & $\ldots$ & $\ldots$ & $22655.60(-5)$ & $22653.55(6)$ & $\ldots$ & $\ldots$ \\
\hline 9.5 & $\ldots$ & $22860.44(-16)$ & $22642.52(2)$ & $22639.65(-15)$ & $\ldots$ & $\ldots$ \\
\hline 10.5 & $\ldots$ & $\ldots$ & $22627.20(-7)$ & $22623.97(0)$ & $\ldots$ & $22406.49(3)$ \\
\hline 11.5 & $\ldots$ & $\ldots$ & $\ldots$ & 22605.91(10) & $\ldots$ & $22368.84(-2)$ \\
\hline 12.5 & $\ldots$ & $\ldots$ & $\ldots$ & $22585.43(31)$ & $22324.83(15)$ & $22329.32(0)$ \\
\hline 13.5 & $\cdots$ & 22859.29(14) & $\cdots$ & $22561.78(15)$ & $22282.44(14)$ & $\ldots$ \\
\hline 14.5 & $\ldots$ & $\ldots$ & $\ldots$ & 22535.23(19) & $\ldots$ & $\ldots$ \\
\hline 15.5 & $\ldots$ & $\ldots$ & $22512.25(28)$ & $22504.95(-6)$ & $22190.20(11)$ & 22197.44(39) \\
\hline 16.5 & $\ldots$ & $22817.87(-15)$ & $22479.09(19)$ & $22471.01(-9)$ & $22139.68(1)$ & $22147.78(30)$ \\
\hline 17.5 & $\ldots$ & $\ldots$ & & $22432.69(-11)$ & & $22094.67(12)$ \\
\hline 18.5 & $\ldots$ & $\ldots$ & $22399.01(-3)$ & $22389.38(-9)$ & $22027.97(-22)$ & $22037.83(6)$ \\
\hline 19.5 & $\ldots$ & $\ldots$ & $22350.69(-17)$ & $22339.95(-42)$ & $\ldots$ & $\ldots$ \\
\hline 20.5 & $\ldots$ & $\ldots$ & $22295.81(-16)$ & $22284.43(-13)$ & $\ldots$ & $\ldots$ \\
\hline 21.5 & $\ldots$ & $\ldots$ & $22233.08(-13)$ & $22220.88(1)$ & $\ldots$ & $\ldots$ \\
\hline 22.5 & $\ldots$ & $\ldots$ & $22161.33(13)$ & $\ldots$ & $\ldots$ & $\ldots$ \\
\hline 23.5 & $22489.41(-41)$ & & $22078.47(29)$ & $\ldots$ & $\ldots$ & $\ldots$ \\
\hline$J$ & R22ff & R22ee & Q22ef & Q22fe & P22ff & P22ee \\
\hline 2.5 & $\ldots$ & $\ldots$ & & & $\ldots$ & $\ldots$ \\
\hline 3.5 & $\ldots$ & $\ldots$ & $22693.20(21)$ & $22693.66(-2)$ & $\ldots$ & $\ldots$ \\
\hline 4.5 & $\ldots$ & $\ldots$ & $22685.83(9)$ & $\ldots$ & $\ldots$ & $\ldots$ \\
\hline 5.5 & $\ldots$ & $\ldots$ & $\ldots$ & $22678.37(-11)$ & $\ldots$ & $\ldots$ \\
\hline 6.5 & $\cdots$ & $\cdots$ & $22666.75(-3)$ & $22668.65(-1)$ & $\cdots$ & $22509.21(-5)$ \\
\hline 7.5 & $\ldots$ & $\ldots$ & $22654.78(4)$ & $22657.04(-10)$ & $\ldots$ & $\ldots$ \\
\hline 8.5 & $\ldots$ & $\ldots$ & $\ldots$ & $22643.80(5)$ & $\ldots$ & $\ldots$ \\
\hline 9.5 & $\ldots$ & $\ldots$ & $22624.58(-14)$ & $22628.27(-5)$ & & $\ldots$ \\
\hline 10.5 & $\ldots$ & $\ldots$ & $22606.01(-37)$ & $\ldots$ & $22369.74(-6)$ & \\
\hline 11.5 & $\ldots$ & $\ldots$ & $22585.43(-8)$ & $\ldots$ & $22330.07(-5)$ & $22324.83(-30)$ \\
\hline 12.5 & $22859.29(-4)$ & $\ldots$ & $22561.78(-8)$ & $\ldots$ & $\ldots$ & $22282.44(-15)$ \\
\hline 13.5 & $\ldots$ & $\ldots$ & $22535.23(10)$ & $\ldots$ & $\ldots$ & $\ldots$ \\
\hline 14.5 & $\ldots$ & $\ldots$ & $22504.95(-2)$ & $22512.25(-10)$ & $22197.44(-4)$ & $22190.20(9)$ \\
\hline 15.5 & $22817.87(5)$ & $\ldots$ & 22471.01(7) & $22479.09(-9)$ & $22147.78(-4)$ & 22139.68(12) \\
\hline 16.5 & $\ldots$ & $\ldots$ & $22432.69(16)$ & & $22094.67(-12)$ & $\ldots$ \\
\hline 17.5 & $\ldots$ & $\ldots$ & $22389.38(28)$ & $22399.01(-14)$ & $22037.83(-9)$ & $22027.97(11)$ \\
\hline 18.5 & $\ldots$ & $\ldots$ & $22339.90(0)$ & $22350.69(-20)$ & $\ldots$ & $\ldots$ \\
\hline 19.5 & $\ldots$ & $\ldots$ & $22283.93(-6)$ & $22295.81(-12)$ & $\ldots$ & $\ldots$ \\
\hline 20.5 & $\ldots$ & $\ldots$ & $22220.34(12)$ & $22233.08(-3)$ & $\ldots$ & $\ldots$ \\
\hline 21.5 & $\ldots$ & & $\ldots$ & $22161.33(30)$ & $\ldots$ & $\ldots$ \\
\hline 22.5 & $\ldots$ & $22489.41(-15)$ & $\ldots$ & $22078.47(51)$ & $\ldots$ & $\ldots$ \\
\hline 23.5 & $\ldots$ & $\ldots$ & $\ldots$ & $\ldots$ & $\ldots$ & $\ldots$ \\
\hline
\end{tabular}


T. Masseron et al.: $\mathrm{CH}$ in stellar atmospheres: an extensive linelist

Table A.2. continued.

\begin{tabular}{|c|c|c|c|c|c|c|}
\hline \multicolumn{7}{|c|}{$5-5$} \\
\hline$J$ & $\mathrm{R} 11 \mathrm{ff}$ & R11ee & Q11ef & Q11fe & P11ee & P11ff \\
\hline 2.5 & $22330.87(-17)$ & $22330.87(-4)$ & & & $\ldots$ & $\ldots$ \\
\hline 3.5 & $22344.29(-20)$ & $22344.29(10)$ & $22261.95(-38)$ & $22261.95(-8)$ & $\ldots$ & $\ldots$ \\
\hline 4.5 & $22354.89(0)$ & $22354.24(-11)$ & $22252.58(-9)$ & $22252.58(45)$ & $\ldots$ & $\ldots$ \\
\hline 5.5 & $22362.19(5)$ & $\ldots$ & $\ldots$ & & $\ldots$ & $\ldots$ \\
\hline 6.5 & $22366.44(33)$ & $\ldots$ & $22225.42(67)$ & $22223.30(-26)$ & $\ldots$ & $\ldots$ \\
\hline 7.5 & $22366.44(-14)$ & $\ldots$ & $22206.17(-10)$ & $22204.69(3)$ & $\ldots$ & $\ldots$ \\
\hline 8.5 & $\ldots$ & $\ldots$ & $22184.39(-12)$ & $22182.57(13)$ & $\ldots$ & $\ldots$ \\
\hline 9.5 & $22355.79(-8)$ & $22353.19(-8)$ & $22159.07(-18)$ & $22156.46(-19)$ & $\ldots$ & $\ldots$ \\
\hline 10.5 & $\ldots$ & $\ldots$ & $22130.08(-10)$ & $22127.38(37)$ & $\ldots$ & $\ldots$ \\
\hline 11.5 & $22327.03(-12)$ & $\ldots$ & $\ldots$ & 22093.54(39) & $\ldots$ & $\ldots$ \\
\hline 12.5 & 22305.11(29) & $\ldots$ & $22059.42(30)$ & $22054.75(8)$ & $\ldots$ & $\ldots$ \\
\hline 13.5 & $\ldots$ & $\ldots$ & $22016.43(25)$ & 22011.09(7) & $\ldots$ & $\ldots$ \\
\hline 14.5 & $\ldots$ & $\ldots$ & $21967.71(21)$ & $21961.29(-32)$ & $\ldots$ & $\ldots$ \\
\hline 15.5 & $22197.89(15)$ & $22191.04(-3)$ & $21912.29(-5)$ & $21906.29(61)$ & $\ldots$ & $\ldots$ \\
\hline 16.5 & $22145.62(11)$ & & & $21842.11(-20)$ & & \\
\hline$J$ & R22ff & R22ee & Q22ef & Q22fe & P22ff & P22ee \\
\hline 1.5 & $22336.55(-2)$ & $22336.55(-20)$ & $\ldots$ & $\ldots$ & $\ldots$ & $\ldots$ \\
\hline 2.5 & $\ldots$ & $\ldots$ & $\ldots$ & $\ldots$ & $\ldots$ & $\ldots$ \\
\hline 3.5 & $\ldots$ & $\ldots$ & $\ldots$ & $\ldots$ & $\ldots$ & $\ldots$ \\
\hline 4.5 & $\ldots$ & $\ldots$ & $\ldots$ & $\ldots$ & $\ldots$ & $\ldots$ \\
\hline 5.5 & $\ldots$ & $\ldots$ & $\ldots$ & $\ldots$ & $\ldots$ & $\ldots$ \\
\hline 6.5 & $\ldots$ & $\ldots$ & 22206.17(4) & $\ldots$ & $\ldots$ & $\ldots$ \\
\hline 7.5 & $\ldots$ & $\ldots$ & $22183.46(-15)$ & $22185.82(-8)$ & $\ldots$ & $\ldots$ \\
\hline 8.5 & $\ldots$ & $\ldots$ & $22157.49(-8)$ & $22160.49(8)$ & $\ldots$ & $\ldots$ \\
\hline 9.5 & $\ldots$ & $\ldots$ & 22128.66(93) & 22131.15(0) & $\ldots$ & $\ldots$ \\
\hline 10.5 & $\ldots$ & $\ldots$ & $22093.54(-14)$ & $\ldots$ & $\ldots$ & $\ldots$ \\
\hline 11.5 & $\ldots$ & $22305.11(-34)$ & $22054.75(-28)$ & $22059.42(-37)$ & $\ldots$ & $\ldots$ \\
\hline 12.5 & $\ldots$ & $\ldots$ & $22011.09(-15)$ & $22016.43(-30)$ & $\ldots$ & $\ldots$ \\
\hline 13.5 & $\ldots$ & $\ldots$ & $21961.29(-40)$ & $21967.71(-23)$ & $\ldots$ & $\ldots$ \\
\hline 14.5 & 22191.04(6) & $22197.89(-14)$ & $21906.29(66)$ & $21912.29(-38)$ & $\ldots$ & $\ldots$ \\
\hline 15.5 & $\ldots$ & $22145.62(-9)$ & $21842.11(-4)$ & $\ldots$ & $\ldots$ & $\ldots$ \\
\hline 16.5 & $\ldots$ & $\ldots$ & $\ldots$ & $\ldots$ & $\ldots$ & $\ldots$ \\
\hline
\end{tabular}

Table A.3. Vacuum wavenumbers $\left(\mathrm{cm}^{-1}\right)$ of clean CH B-X transitions in CS 22942-019 used for the calculation of the constants.

\begin{tabular}{|c|c|c|c|c|c|c|}
\hline \multicolumn{7}{|c|}{$0-0$} \\
\hline$J$ & R11ff & R11ee & Q11ef & Q11fe & P11ee & P11ff \\
\hline 0.5 & $\ldots$ & $\ldots$ & $\ldots$ & $\ldots$ & $\ldots$ & $\ldots$ \\
\hline 1.5 & $\ldots$ & $\ldots$ & $\ldots$ & $\ldots$ & $\ldots$ & $\ldots$ \\
\hline 2.5 & $\ldots$ & $\ldots$ & $\ldots$ & $\ldots$ & $\ldots$ & $\ldots$ \\
\hline 3.5 & $\ldots$ & $\ldots$ & $\ldots$ & $\ldots$ & $\ldots$ & $\ldots$ \\
\hline 4.5 & $\ldots$ & $\ldots$ & $\ldots$ & $\ldots$ & $\ldots$ & $\ldots$ \\
\hline 5.5 & $\ldots$ & $\ldots$ & $\ldots$ & $\ldots$ & $\ldots$ & $\ldots$ \\
\hline 6.5 & $\ldots$ & $\ldots$ & $\ldots$ & $\ldots$ & $\ldots$ & $\ldots$ \\
\hline 7.5 & $\ldots$ & $\ldots$ & $\ldots$ & $\ldots$ & $\ldots$ & $\ldots$ \\
\hline 8.5 & $25818.70(-2)$ & $\ldots$ & $\ldots$ & $\ldots$ & $\ldots$ & $\ldots$ \\
\hline 9.5 & $25811.97(5)$ & $\ldots$ & $\ldots$ & $\ldots$ & $\ldots$ & $25346.72(-2)$ \\
\hline 10.5 & $25800.62(0)$ & $\ldots$ & $\ldots$ & $\ldots$ & $\ldots$ & $25290.21(-4)$ \\
\hline 11.5 & $25784.50(-3)$ & $\ldots$ & $\ldots$ & $\ldots$ & $\ldots$ & $25230.22(6)$ \\
\hline 12.5 & $25763.17(-16)$ & $\ldots$ & $\ldots$ & $25448.78(-9)$ & $\ldots$ & $25166.27(-1)$ \\
\hline 13.5 & $25736.64(4)$ & $\ldots$ & $\ldots$ & $25401.09(0)$ & $\ldots$ & $25098.40(1)$ \\
\hline 14.5 & $25703.89(2)$ & $\ldots$ & $\ldots$ & $25348.17(0)$ & $\ldots$ & $25026.15(-4)$ \\
\hline 15.5 & 25664.56(3) & $\ldots$ & $\ldots$ & & $\ldots$ & $\ldots$ \\
\hline 16.5 & 25617.93(11) & $\ldots$ & $\ldots$ & $25225.06(8)$ & $\ldots$ & $24867.48(2)$ \\
\hline 17.5 & $25562.84(9)$ & $\ldots$ & $\ldots$ & $25153.60(19)$ & $\ldots$ & $24779.83(-11)$ \\
\hline 18.5 & & $\ldots$ & $\ldots$ & $25074.30(32)$ & $\ldots$ & $24686.15(6)$ \\
\hline 19.5 & $25422.37(58)$ & $\ldots$ & $\ldots$ & $24985.75(36)$ & $\ldots$ & $24585.13(16)$ \\
\hline 20.5 & $25331.48(-27)$ & $\ldots$ & $\ldots$ & $24886.24(33)$ & $\ldots$ & $24475.95(65)$ \\
\hline 21.5 & $25226.27(161)$ & $\ldots$ & $\ldots$ & $24773.20(2)$ & $\ldots$ & $24355.86(49)$ \\
\hline 22.5 & $\ldots$ & $\ldots$ & $\ldots$ & $\ldots$ & $\ldots$ & $24222.96(14)$ \\
\hline
\end{tabular}

Notes. The numbers in parentheses are the observed minus calculated value. The numbers in italics are predissociation lines where the accuracy of the position is low. 
Table A.3. continued.

\begin{tabular}{|c|c|c|c|c|c|c|}
\hline 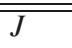 & $\overline{\bar{R} 22 \mathrm{ff}}$ & 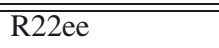 & $\overline{\text { Q22ef }}$ & $\overline{\text { Q22fe }}$ & $\overline{\mathrm{P} 22 \mathrm{ff}}$ & $\overline{\text { P22ee }}$ \\
\hline 0.5 & $\ldots$ & $\ldots$ & $\ldots$ & $\ldots$ & $\ldots$ & $\ldots$ \\
\hline 1.5 & $\ldots$ & $\ldots$ & $\ldots$ & $\ldots$ & $\ldots$ & $\ldots$ \\
\hline 2.5 & $\ldots$ & $\ldots$ & $\ldots$ & $\ldots$ & $\ldots$ & $\ldots$ \\
\hline 3.5 & $\ldots$ & $\ldots$ & $\ldots$ & $\ldots$ & $\ldots$ & $\ldots$ \\
\hline 4.5 & $\ldots$ & $\ldots$ & $\ldots$ & $\ldots$ & $\ldots$ & $\ldots$ \\
\hline 5.5 & $\ldots$ & $\ldots$ & $\ldots$ & $\ldots$ & $\ldots$ & $\cdots$ \\
\hline 6.5 & $\ldots$ & $\ldots$ & $\ldots$ & $\ldots$ & $\ldots$ & $\ldots$ \\
\hline 7.5 & $\ldots$ & $\ldots$ & $\ldots$ & $\ldots$ & $\ldots$ & $\cdots$ \\
\hline 8.5 & $\ldots$ & $25813.72(13)$ & $\ldots$ & $\ldots$ & $25348.32(-5)$ & $\ldots$ \\
\hline 9.5 & $\ldots$ & 25802.33(17) & $\ldots$ & $\ldots$ & 25291.78(3) & $\ldots$ \\
\hline 10.5 & $\ldots$ & $25785.95(-2)$ & $\ldots$ & $\ldots$ & 25231.56(1) & $\ldots$ \\
\hline 11.5 & $\ldots$ & $25764.50(-17)$ & $25449.75(-4)$ & $\ldots$ & $25167.66(7)$ & $\ldots$ \\
\hline 12.5 & $\ldots$ & $25737.98(11)$ & $25401.83(-8)$ & $\ldots$ & $25099.60(-2)$ & $\ldots$ \\
\hline 13.5 & $\ldots$ & $25704.87(-20)$ & 25348.90(1) & $\ldots$ & 25027.34(-2) & $\ldots$ \\
\hline 14.5 & $\ldots$ & $\ldots$ & $\ldots$ & $\ldots$ & $\ldots$ & $\ldots$ \\
\hline 15.5 & $\ldots$ & 25618.92(0) & $25225.51(-4)$ & $\ldots$ & 24868.53(1) & $\ldots$ \\
\hline 16.5 & $\ldots$ & 25563.82(3) & 25153.91(1) & $\ldots$ & $24780.94(-3)$ & $\ldots$ \\
\hline 17.5 & $\ldots$ & & $25074.30(-10)$ & $\ldots$ & $24687.07(-1)$ & $\ldots$ \\
\hline 18.5 & $\ldots$ & $25422.37(-38)$ & $24985.75(0)$ & $\ldots$ & $24586.04(12)$ & $\ldots$ \\
\hline 19.5 & $\ldots$ & $25331.48(-119)$ & $24886.24(3)$ & $\ldots$ & $24476.97(75)$ & $\ldots$ \\
\hline 20.5 & $\ldots$ & $25226.27(73)$ & $24773.20(-23)$ & $\ldots$ & $24355.86(-39)$ & $\ldots$ \\
\hline 21.5 & $\ldots$ & $\ldots$ & $\ldots$ & $\ldots$ & $24222.96(-71)$ & $\ldots$ \\
\hline \multirow[t]{2}{*}{22.5} & $\ldots$ & $\ldots$ & $\ldots$ & $\ldots$ & $\ldots$ & $\ldots$ \\
\hline & & & $0-1$ & & & \\
\hline$J$ & R11ff & R11ee & Q11ef & Q11fe & P11ee & P11ff \\
\hline 13.5 & $\ldots$ & $\ldots$ & $\ldots$ & & $\ldots$ & $\ldots$ \\
\hline 14.5 & 23081.21(2) & $\ldots$ & $\ldots$ & $22725.85(9)$ & $\ldots$ & $\ldots$ \\
\hline 15.5 & 23057.47(2) & $\ldots$ & $\ldots$ & & $\ldots$ & $\ldots$ \\
\hline 16.5 & $\ldots$ & $\ldots$ & $\ldots$ & $22634.88(3)$ & $\ldots$ & $\ldots$ \\
\hline 17.5 & $\ldots$ & $\ldots$ & $\ldots$ & $\ldots$ & $\ldots$ & $\ldots$ \\
\hline 18.5 & $\ldots$ & $\ldots$ & $\ldots$ & $22520.41(32)$ & $\ldots$ & 22131.84(5) \\
\hline 19.5 & $\ldots$ & $\ldots$ & $\ldots$ & $22451.48(37)$ & $\ldots$ & $\ldots$ \\
\hline 20.5 & $\ldots$ & $\ldots$ & $\ldots$ & $22372.70(50)$ & $\ldots$ & 21961.10(3) \\
\hline$J$ & R22ff & R22ee & Q22ef & Q22fe & P22ff & P22ee \\
\hline 13.5 & $\ldots$ & $\ldots$ & $22726.42(-7)$ & $\ldots$ & $\ldots$ & $\ldots$ \\
\hline 14.5 & $\ldots$ & 23058.59(1) & & $\ldots$ & $\ldots$ & $\ldots$ \\
\hline 15.5 & $\ldots$ & $\ldots$ & $22635.39(-3)$ & $\ldots$ & $\ldots$ & $\cdots$ \\
\hline 16.5 & $\ldots$ & $\ldots$ & $\ldots$ & $\ldots$ & $\ldots$ & $\ldots$ \\
\hline 17.5 & $\ldots$ & $\ldots$ & $22520.41(-12)$ & $\ldots$ & $22132.87(12)$ & $\ldots$ \\
\hline 18.5 & $\ldots$ & $\ldots$ & $22451.48(0)$ & $\ldots$ & & $\ldots$ \\
\hline 19.5 & $\ldots$ & $\ldots$ & $22372.70(18)$ & $\ldots$ & $21962.02(4)$ & $\ldots$ \\
\hline \multirow[t]{2}{*}{20.5} & $\ldots$ & $\ldots$ & $\ldots$ & $\ldots$ & $\ldots$ & $\ldots$ \\
\hline & & & $1-0$ & & & \\
\hline$J$ & $\mathrm{R} 11 \mathrm{ff}$ & R11ee & Q11ef & Q11fe & P11ee & P11ff \\
\hline 4.5 & & $\ldots$ & $\cdots$ & .. & $\cdots$ & \\
\hline 5.5 & 27545.34(4) & $\ldots$ & $\ldots$ & $27413.23(1)$ & $\ldots$ & $27304.25(-5)$ \\
\hline 6.5 & $27528.43(16)$ & $\ldots$ & $\ldots$ & $27375.24(5)$ & $\ldots$ & $27245.60(0)$ \\
\hline 7.5 & 27503.58(9) & $\ldots$ & $\ldots$ & $27330.17(17)$ & $\ldots$ & $27180.45(10)$ \\
\hline 8.5 & $27470.39(2)$ & $\ldots$ & $\ldots$ & $27277.15(-10)$ & $\ldots$ & 27108.33(7) \\
\hline 9.5 & 27428.13(2) & $\ldots$ & $\ldots$ & $27216.47(11)$ & $\ldots$ & $27028.91(-5)$ \\
\hline 10.5 & 27375.70(4) & $\ldots$ & $\ldots$ & 27146.76(17) & $\ldots$ & $26941.79(-11)$ \\
\hline 11.5 & $27312.23(64)$ & $\ldots$ & $\ldots$ & $27066.68(-23)$ & $\ldots$ & $26846.26(-9)$ \\
\hline 12.5 & $27233.37(-64)$ & $\ldots$ & $\ldots$ & 26976.32(39) & $\ldots$ & $26741.50(17)$ \\
\hline 13.5 & $\ldots$ & $\ldots$ & $\ldots$ & $26872.12(35)$ & $\ldots$ & $26626.07(62)$ \\
\hline 14.5 & $\ldots$ & $\ldots$ & $\ldots$ & $\ldots$ & $\ldots$ & $26495.18(-170)$ \\
\hline$J$ & R22ff & R22ee & Q22ef & Q22fe & P22ff & P22ee \\
\hline 4.5 & $\ldots$ & $27548.20(20)$ & $27415.68(-4)$ & $\ldots$ & $27306.93(-3)$ & $\ldots$ \\
\hline 5.5 & $\ldots$ & $27530.63(6)$ & $27377.27(2)$ & $\ldots$ & $27247.88(3)$ & $\ldots$ \\
\hline 6.5 & $\ldots$ & $27505.62(12)$ & 27331.91(17) & $\ldots$ & $27182.45(14)$ & $\ldots$ \\
\hline 7.5 & $\ldots$ & $27472.22(7)$ & $27278.71(-2)$ & $\ldots$ & $27110.20(19)$ & $\ldots$ \\
\hline 8.5 & $\ldots$ & $27429.83(10)$ & $27217.80(15)$ & $\ldots$ & $27030.55(2)$ & $\ldots$ \\
\hline 9.5 & $\ldots$ & $27377.03(-12)$ & $27147.98(27)$ & $\ldots$ & $26943.32(-2)$ & $\ldots$ \\
\hline 10.5 & $\ldots$ & $27312.23(-74)$ & $27067.70(-19)$ & $\ldots$ & $26847.66(-3)$ & $\ldots$ \\
\hline 11.5 & $\ldots$ & $27233.37(-193)$ & $26976.32(-48)$ & $\ldots$ & 26742.74(17) & $\ldots$ \\
\hline 12.5 & $\ldots$ & $\ldots$ & $26872.12(-41)$ & $\ldots$ & $26626.07(-55)$ & $\ldots$ \\
\hline 13.5 & $\ldots$ & $\ldots$ & $\ldots$ & $\ldots$ & $26495.18(-282)$ & $\ldots$ \\
\hline 14.5 & $\ldots$ & $\ldots$ & $\ldots$ & $\ldots$ & $\ldots$ & $\ldots$ \\
\hline
\end{tabular}


T. Masseron et al.: $\mathrm{CH}$ in stellar atmospheres: an extensive linelist

Table A.3. continued.

\begin{tabular}{lllllll}
\hline \hline & & & & & \\
$J$ & $\mathrm{R} 11 \mathrm{ff}$ & $\mathrm{R} 11 \mathrm{ee}$ & $\mathrm{Q} 1 \mathrm{ef}$ & $\mathrm{Q} 11 \mathrm{fe}$ & $\mathrm{P} 11 \mathrm{ee}$ & P11ff \\
\hline 7.5 & $\ldots$ & $\ldots$ & $\ldots$ & $\ldots$ & $\ldots$ & $\ldots$ \\
8.5 & $24775.47(2)$ & $\ldots$ & $\ldots$ & $\ldots$ & $\ldots$ & $24413.37(3)$ \\
9.5 & $\ldots$ & $\ldots$ & $\ldots$ & $24531.08(6)$ & $\ldots$ & $24343.58(8)$ \\
10.5 & $24700.85(14)$ & $\ldots$ & $\ldots$ & $24471.76(-3)$ & $\ldots$ & $24266.94(-1)$ \\
11.5 & $24648.17(-1)$ & $\ldots$ & $\ldots$ & $24403.60(-7)$ & $\ldots$ & $24182.83(-12)$ \\
12.5 & $24585.56(240)$ & $\ldots$ & $\ldots$ & $24325.46(17)$ & $\ldots$ & $24090.70(22)$ \\
13.5 & $\ldots$ & $\ldots$ & $\ldots$ & $24237.35(261)$ & $\ldots$ & $23989.76(158)$ \\
\hline $\mathrm{J}$ & $\mathrm{R} 22 \mathrm{ff}$ & $\mathrm{R} 22 \mathrm{ee}$ & $\mathrm{Q} 22 \mathrm{ef}$ & $\mathrm{Q} 22 \mathrm{fe}$ & $\mathrm{P} 22 \mathrm{ff}$ & $\mathrm{P} 22 \mathrm{ee}$ \\
7.5 & $\ldots$ & $24777.19(1)$ & $\ldots$ & $\ldots$ & $24415.04(1)$ & $\ldots$ \\
8.5 & $\ldots$ & $\ldots$ & $24532.29(1)$ & $\ldots$ & $24345.06(4)$ & $\ldots$ \\
9.5 & $\ldots$ & $24701.77(-39)$ & $24472.84(-4)$ & $\ldots$ & $24268.36(1)$ & $\ldots$ \\
10.5 & $\ldots$ & $24648.17(-135)$ & $24404.61(-2)$ & $\ldots$ & $24184.17(-7)$ & $\ldots$ \\
11.5 & $\ldots$ & $24585.56(114)$ & $24325.46(-68)$ & $\ldots$ & $24091.74(5)$ & $\ldots$ \\
12.5 & $\ldots$ & $\ldots$ & $24237.35(186)$ & $\ldots$ & $23989.76(44)$ & $\ldots$ \\
13.5 & $\ldots$ & $\ldots$ & $\ldots$ & $\ldots$ & $\ldots$ & $\ldots$ \\
\hline
\end{tabular}

Table A.4. Vacuum wavenumbers $\left(\mathrm{cm}^{-1}\right)$ of clean $\mathrm{CH} \mathrm{C}-\mathrm{X}$ transitions in our stellar spectra used for the calculation of the constants.

\begin{tabular}{lllllll}
\hline \hline & & & & & \\
$J$ & R11ff & R11ee & Q11ef & Q11fe & P11ee & P11ff \\
\hline 7.5 & $\ldots$ & $\ldots$ & $\ldots$ & $\ldots$ & $\ldots$ & $\ldots$ \\
8.5 & $\ldots$ & $\ldots$ & $\ldots$ & $\ldots$ & $31192.72(21)$ & $\ldots$ \\
9.5 & $\ldots$ & $\ldots$ & $31381.79(24)$ & $\ldots$ & $\ldots$ & $\ldots$ \\
10.5 & $\ldots$ & $\ldots$ & $31369.38(56)$ & $\ldots$ & $31121.54(30)$ & $\ldots$ \\
11.5 & $\ldots$ & $\ldots$ & $\ldots$ & $\ldots$ & $31083.62(21)$ & $\ldots$ \\
12.5 & $\ldots$ & $\ldots$ & $\ldots$ & $\ldots$ & $31043.85(1)$ & $\ldots$ \\
13.5 & $\ldots$ & $\ldots$ & $31317.60(20)$ & $\ldots$ & $31002.36(2)$ & $\ldots$ \\
14.5 & $\ldots$ & $\ldots$ & $31294.66(-11)$ & $\ldots$ & $\ldots$ & $\ldots$ \\
15.5 & $\ldots$ & $31628.30(-11)$ & $\ldots$ & $\ldots$ & $\ldots$ & $\ldots$ \\
16.5 & $\ldots$ & $31614.50(-26)$ & $\ldots$ & $\ldots$ & $\ldots$ & $\ldots$ \\
\hline$J$ & $\mathrm{R} 22 \mathrm{ff}$ & $\mathrm{R} 22 \mathrm{ee}$ & $\mathrm{Q} 22 \mathrm{ef}$ & $\mathrm{Q} 22 \mathrm{fe}$ & $\mathrm{P} 22 \mathrm{ff}$ & $\mathrm{P} 22 \mathrm{ee}$ \\
7.5 & $\ldots$ & $\ldots$ & $\ldots$ & $\ldots$ & $\ldots$ & $31193.40(-3)$ \\
8.5 & $\ldots$ & $\ldots$ & $\ldots$ & $31382.58(10)$ & $\ldots$ & $\ldots$ \\
9.5 & $\ldots$ & $\ldots$ & $\ldots$ & $31369.38(-19)$ & $\ldots$ & $31121.54(-17)$ \\
10.5 & $\ldots$ & $\ldots$ & $\ldots$ & $\ldots$ & $\ldots$ & $31083.62(-7)$ \\
11.5 & $\ldots$ & $\ldots$ & $\ldots$ & $\ldots$ & $\ldots$ & $31043.85(-11)$ \\
12.5 & $\ldots$ & $\ldots$ & $\ldots$ & $31317.60(-13)$ & $\ldots$ & $31002.36(6)$ \\
13.5 & $\ldots$ & $\ldots$ & $\ldots$ & $\ldots$ & $\ldots$ & $\ldots$ \\
14.5 & $31628.30(27)$ & $\ldots$ & $\ldots$ & $\ldots$ & $\ldots$ & $\ldots$ \\
15.5 & $31614.50(24)$ & $\ldots$ & $\ldots$ & $\ldots$ & & $\ldots$ \\
16.5 & $\ldots$ & & $\ldots$ & & & $\ldots$ \\
\hline
\end{tabular}

Notes. The numbers in parentheses are the observed minus calculated value.

Table A.5. Vacuum wavenumbers $\left(\mathrm{cm}^{-1}\right)$ of clean $\mathrm{CH}$ A-X transitions of ${ }^{13} \mathrm{CH}$ in our stellar spectra used for the calculation of the constants.

\begin{tabular}{lllllll}
\hline \hline & & & $1-1$ & & & \\
$J$ & R11ff & R11ee & Q11ef & Q11fe & P11ee & P11ff \\
\hline 18.5 & $\ldots$ & $\ldots$ & $\ldots$ & $\ldots$ & $\ldots$ & $\ldots$ \\
19.5 & $23758.86(-3)$ & $23747.07(-5)$ & $\ldots$ & $\ldots$ & $\ldots$ & $\ldots$ \\
20.5 & $23783.00(-11)$ & $23770.22(-5)$ & $\ldots$ & $\ldots$ & $\ldots$ & $\ldots$ \\
21.5 & $23805.71(-21)$ & $\ldots$ & $\ldots$ & $\ldots$ & $\ldots$ & $\ldots$ \\
22.5 & $23826.87(-28)$ & $\ldots$ & $\ldots$ & $\ldots$ & $\ldots$ & $\ldots$ \\
23.5 & $23846.14(-42)$ & $\ldots$ & $\ldots$ & $\ldots$ & $\ldots$ & $\ldots$ \\
24.5 & $23863.38(-51)$ & $\ldots$ & $\ldots$ & $\ldots$ & $\ldots$ & $\ldots$ \\
25.5 & $\ldots$ & $\ldots$ & $\ldots$ & $\ldots$ & $\ldots$ & $\ldots$ \\
26.5 & $23890.58(-65)$ & $\ldots$ & $\ldots$ & $\ldots$ & $\ldots$ & $\ldots$ \\
\hline$J$ & $\mathrm{R} 22 \mathrm{ff}$ & $\mathrm{R} 22 \mathrm{ee}$ & $\mathrm{Q} 22 \mathrm{ef}$ & $\mathrm{Q} 22 \mathrm{fe}$ & $\mathrm{P} 22 \mathrm{ee}$ & $\mathrm{P} 22 \mathrm{ff}$ \\
18.5 & $23746.67(7)$ & $23758.86(-1)$ & $\ldots$ & $\ldots$ & $\ldots$ & $\ldots$ \\
19.5 & $23769.60(-6)$ & $23783.00(0)$ & $\ldots$ & $\ldots$ & $\ldots$ & $\ldots$ \\
20.5 & $\ldots$ & $23805.71(-3)$ & $\ldots$ & $\ldots$ & $\ldots$ & $\ldots$ \\
21.5 & $\ldots$ & $23826.87(-2)$ & $\ldots$ & $\ldots$ & $\ldots$ & $\ldots$ \\
22.5 & $\ldots$ & $23846.14(-10)$ & $\ldots$ & $\ldots$ & $\ldots$ & $\ldots$ \\
23.5 & $\ldots$ & $23863.38(-14)$ & $\ldots$ & $\ldots$ & $\ldots$ & $\ldots$ \\
24.5 & $\ldots$ & $\ldots$ & $\ldots$ & $\ldots$ & $\ldots$ & $\ldots$ \\
25.5 & $\ldots$ & $23890.58(-17)$ & $\ldots$ & $\ldots$ & $\ldots$ & $\ldots$ \\
\hline
\end{tabular}

Notes. The numbers in parentheses are the observed minus calculated value. 
Table A.6. Vacuum wavenumbers $\left(\mathrm{cm}^{-1}\right)$ of clean $\mathrm{CH} \mathrm{B}-\mathrm{X}$ transitions of ${ }^{13} \mathrm{CH}$ in our stellar spectra used for the calculation of the constants.

\begin{tabular}{|c|c|c|c|c|c|c|}
\hline \multicolumn{7}{|c|}{$\overline{0-0}$} \\
\hline$J$ & $\mathrm{R} 11 \mathrm{ff}$ & R11ee & Q11ef & Q11fe & P11ee & P11ff \\
\hline 16.5 & $\ldots$ & $\ldots$ & .. & $25229.71(-1)$ & ... & $24873.91(3)$ \\
\hline 17.5 & $\ldots$ & $\ldots$ & $\ldots$ & $25158.98(7)$ & $\ldots$ & $24787.08(-2)$ \\
\hline 18.5 & $25498.69(-384)$ & $\ldots$ & $\ldots$ & $25080.34(-4)$ & $\ldots$ & $24693.96(-16)$ \\
\hline 19.5 & $\ldots$ & $\ldots$ & $\ldots$ & 24992.81(1) & $\ldots$ & $24593.72(-26)$ \\
\hline 20.5 & $\ldots$ & $\ldots$ & $\ldots$ & $24894.23(-14)$ & $\ldots$ & $24485.60(19)$ \\
\hline$J$ & R22ff & R22ee & Q22ef & Q22fe & P22ee & P22ff \\
\hline 15.5 & $\ldots$ & $\ldots$ & $25229.71(-56)$ & $\ldots$ & $24874.90(-2)$ & $\ldots$ \\
\hline 16.5 & $\ldots$ & $\ldots$ & $25158.98(-40)$ & $\ldots$ & $\ldots$ & $\ldots$ \\
\hline 17.5 & $\ldots$ & $25503.44(-6)$ & $25080.34(-44)$ & $\ldots$ & $24694.87(-19)$ & $\ldots$ \\
\hline 18.5 & $\ldots$ & $\ldots$ & $24992.81(-33)$ & $\ldots$ & $24594.69(-20)$ & $\ldots$ \\
\hline 19.5 & $\ldots$ & $\ldots$ & $24894.23(-42)$ & $\ldots$ & $24485.60(-69)$ & $\ldots$ \\
\hline & & & $1-0$ & & & \\
\hline$J$ & R11ff & R11ee & Q11ef & Q11fe & P11ee & P11ff \\
\hline 6.5 & $27525.72(12)$ & $\ldots$ & $\ldots$ & $\ldots$ & $\ldots$ & $\ldots$ \\
\hline 7.5 & $27501.19(12)$ & $\ldots$ & $\ldots$ & $\ldots$ & $\ldots$ & $\ldots$ \\
\hline 8.5 & $\ldots$ & $\ldots$ & $\ldots$ & $27276.39(23)$ & $\ldots$ & $\ldots$ \\
\hline 9.5 & $\ldots$ & $\ldots$ & $\ldots$ & $27216.02(31)$ & $\ldots$ & $\ldots$ \\
\hline 10.5 & $\ldots$ & $\ldots$ & $\ldots$ & $\ldots$ & $\ldots$ & $\ldots$ \\
\hline 11.5 & $\ldots$ & $\ldots$ & $\ldots$ & $27067.69(23)$ & $\ldots$ & $\ldots$ \\
\hline 12.5 & $\ldots$ & $\ldots$ & & $26975.59(-203)$ & . & $\ldots$ \\
\hline$J$ & R22ff & R22ee & Q22ef & Q22fe & P22ee & P22ff \\
\hline 6.5 & $\ldots$ & $\ldots$ & $\ldots$ & $\ldots$ & $\ldots$ & $\ldots$ \\
\hline 7.5 & $\ldots$ & $\ldots$ & $\ldots$ & $\ldots$ & $\ldots$ & $\ldots$ \\
\hline 8.5 & $\ldots$ & $\ldots$ & $\cdots$ & $\cdots$ & $\ldots$ & $\cdots$ \\
\hline 9.5 & $\ldots$ & $\ldots$ & & $\ldots$ & $\ldots$ & $\ldots$ \\
\hline 10.5 & $\ldots$ & $\ldots$ & $27067.69(-76)$ & $\ldots$ & $26849.68(42)$ & $\ldots$ \\
\hline 11.5 & $\ldots$ & $\ldots$ & $26975.59(-290)$ & $\ldots$ & $\ldots$ & $\ldots$ \\
\hline
\end{tabular}

Notes. The numbers in parentheses are the observed minus calculated value. The numbers in italic are predissociation lines where the accuracy of the position is low.

Table A.7. Vacuum wavenumbers $\left(\mathrm{cm}^{-1}\right)$ of clean $\mathrm{CH} \mathrm{C}-\mathrm{X}$ transitions of ${ }^{13} \mathrm{CH}$ in our stellar spectra used for the calculation of the constants.

\begin{tabular}{lllllll}
\hline \hline & & & $0-0$ & & \\
$J$ & R11ff & R11ee & Q11ef & Q11fe & P11ee & P11ff \\
\hline 15.5 & $\ldots$ & $32223.03(9)$ & $\ldots$ & $\ldots$ & $\ldots$ & $\ldots$ \\
16.5 & $\ldots$ & $\ldots$ & $\ldots$ & $\ldots$ & $31365.64(-25)$ & $\ldots$ \\
17.5 & $\ldots$ & $32266.81(-2)$ & $\ldots$ & $\ldots$ & $31341.06(-23)$ & $\ldots$ \\
18.5 & $\ldots$ & $\ldots$ & $\ldots$ & $\ldots$ & $\ldots$ & $\ldots$ \\
19.5 & $\ldots$ & $\ldots$ & $\ldots$ & $\ldots$ & $\ldots$ & $\ldots$ \\
20.5 & $\ldots$ & $\ldots$ & $\ldots$ & $\ldots$ & $31266.86(-95)$ & $\ldots$ \\
\hline$J$ & $\mathrm{R} 22 \mathrm{ff}$ & $\mathrm{R} 22 \mathrm{ee}$ & $\mathrm{Q} 22 \mathrm{ef}$ & $\mathrm{Q} 22 \mathrm{fe}$ & $\mathrm{P} 22 \mathrm{ee}$ & P22ff \\
14.5 & $32223.03(49)$ & $\ldots$ & $\ldots$ & $\ldots$ & $\ldots$ & $\ldots$ \\
15.5 & $\ldots$ & $\ldots$ & $\ldots$ & $\ldots$ & $\ldots$ & $31365.64(20)$ \\
16.5 & $32266.81(64)$ & $\ldots$ & $\ldots$ & $\ldots$ & $\ldots$ & $31341.06(34)$ \\
17.5 & $\ldots$ & $\ldots$ & $\ldots$ & $\ldots$ & $\ldots$ & $\ldots$ \\
18.5 & $\ldots$ & $\ldots$ & $\ldots$ & $\ldots$ & $\ldots$ & $\ldots$ \\
19.5 & $\ldots$ & $\ldots$ & $\ldots$ & $\ldots$ & $\ldots$ & $31266.86(-4)$ \\
20.5 & $\ldots$ & $\ldots$ & $\ldots$ & $\ldots$ & $\ldots$ & $\ldots$ \\
\hline
\end{tabular}

Notes. The numbers in parentheses are the observed minus calculated value.

\section{References}

Alvarez, R., \& Plez, B. 1998, A\&A, 330, 1109

Asplund, M. 2005, ARA\&A, 43, 481

Bembenek, Z., Ke, R., \& Rytel, M. 1997, J. Mol. Spectrosc., 183, 1

Bernath, P., McElroy, C., Abrams, M., et al. 2005, Geophys. Res. Lett. 32, L15S01, see also http: //www.ace.uwaterloo.ca/

Bernath, P. F. 2009, Int. Rev. Phys. Chem., 28, 681

Bernath, P. F., Brazier, C. R., Olsen, T., et al. 1991, J. Mol. Spectr., 147, 16

Bidelman, W. P., \& Keenan, P. C. 1951, ApJ, 114, 473

Biémont, E., Palmeri, P., \& Quinet, P. 1999, Ap\&SS, 269, 635

Bond, H. E., \& Neff, J. S. 1969, ApJ, 158, 1235

Brooks, N. H., \& Smith, W. H. 1974, ApJ, 194, 513

Brown, J. M., Colbourn, E. A., Watson, J. K. G., \& Wayne, F. D. 1979, J. Mol. Spectr., 74, 294
Brzozowski, J., Bunker, P., Elander, N., \& Erman, P. 1976, ApJ, 207, 414 Christlieb, N., Bessell, M. S., Beers, T. C., et al. 2002, Nature, 419, 904 Colin, R., \& Bernath, P. F. 2010, J. Mol. Spectr., 263, 120

Decin, L., Vandenbussche, B., Waelkens, C., et al. 2003, A\&A, 400, 709

Elander, N., Hehenberger, M., \& Bunker, P. 1979, Phys. Scr., 20, 631

Elander, N., \& Smith, W. H. 1973, ApJ, 184, 663

Fink, U., Combi, M., \& Disanti, M. A. 1992, in Asteroids, Comets, Meteors 1991, eds. A. W. Harris, \& E. Bowell, 187

Fulara, J., \& Krełowski, J. 2000, New Astron. Rev., 44, 581

Gustafsson, B., Edvardsson, B., Eriksson, K., et al. 2008, A\&A, 486, 951

Gustafsson, B., Meléndez, J., Asplund, M., \& Yong, D. 2010, Ap\&SS, 328, 185

Heimer, T. 1932, Z. Phys., 78, 771

Herbig, G. H. 1975, ApJ, 196, 129 
T. Masseron et al.: $\mathrm{CH}$ in stellar atmospheres: an extensive linelist

Herbig, G. H. 1995, ARA\&A, 33, 19

Herzberg, G. 1950, Molecular spectra and molecular structure, Vol.1: Spectra of diatomic molecules, ed. Van Nostrand Reinhold

Herzberg, G., \& Johns, J. W. C. 1969, ApJ, 158, 399

Hettema, H., \& Yarkony, D. R. 1994, J. Chem. Phys., 100, 8991

Heurlinger, T., \& Hulthen, E. 1919, Z. Wiss. Photogr. Photophys. Photochem., 18,241

Hill, V., Plez, B., Cayrel, R., et al. 2002, A\&A, 387, 560

Jackson, M., Zink, L. R., McCarthy, M. C., Perez, L., \& Brown, J. M. 2008, J. Mol. Spectr., 247, 128

Jorgensen, U. G. 1994, A\&A, 284, 179

Jorgensen, U. G., Larsson, M., Iwamae, A., \& Yu, B. 1996, A\&A, 315, 204

Kalemos, A., Mavridis, A., \& Metropoulos, A. 1999, J. Chem. Phys., 111, 9536

Käppeler, F., Gallino, R., Bisterzo, S., \& Aoki, W. 2011, Rev. Mod. Phys., 83, 157

Kato, H., \& Baba, M. 1995, Chem. Rev., 95, 2311

Kepa, R. 1996, J. Mol. Spectr., 178, 189

Kumar, A., Hsiao, C.-C., Hung, W.-C., \& Lee, Y.-P. 1998, J. Chem. Phys., 109, 3824

Kupka, F., Piskunov, N., Ryabchikova, T. A., Stempels, H. C., \& Weiss, W. W. 1999, A\&AS, 138, 119

Larsson, M. 1983, A\&A, 128, 291

Li, G., Harrison, J. J., Ram, R. S., Western, C. M., \& Bernath, P. F. 2012, J. Quant. Spectr. Rad. Transf., 113, 67

Li, X., \& Lee, Y.-P. 1999, J. Chem. Phys., 111, 4942

Li, X., Kumar, A., Hsiao, C.-C., \& Lee, Y.-P. 1999, J. Phys. Chem. A, 103, 6162

Lie, G. C., Hinze, J., \& Liu, B. 1973, J. Chem. Phys., 59, 1887

Luque, J., \& Crosley, D. 1999, in SRI Int. Rep. MP, Vol. 99, 009
Luque, J., \& Crosley, D. R. 1996a, J. Chem. Phys., 104, 2146

Luque, J., \& Crosley, D. R. 1996b, J. Chem. Phys., 104, 3907

Masseron, T. 2006, Ph.D. Thesis, Observatoire de Paris, France

Masseron, T., van Eck, S., Famaey, B., et al. 2006, A\&A, 455, 1059

Masseron, T., Johnson, J. A., Plez, B., et al. 2010, A\&A, 509, A93

Masseron, T., Johnson, J. A., Lucatello, S., et al. 2012, ApJ, 751, 14

McWilliam, A., \& Smith, V. V. 1984, BAAS, 16, 973

Metropoulos, A., \& Mavridis, A. 2000, Chem. Phys. Lett., 331, 89

Para, A. 1996, J. Phys. B At. Mol. Phys., 29, 5765

Plez, B. 2008, Phys. Scripta T, 133, 014003

Plez, B. 2012, Turbospectrum: Code for spectral synthesis, astrophysics Source Code Library

Sauval, A. J., \& Tatum, J. B. 1984, ApJS, 56, 193

Sheffer, Y., \& Federman, S. R. 2007, ApJ, 659, 1352

Shelyag, S., Schüssler, M., Solanki, S. K., Berdyugina, S. V., \& Vögler, A. 2004, A\&A, 427, 335

Shidei, T. 1936, Japanese J. Phys., 11, 23

Steimle, T. C., Woodward, D. R., \& Brown, J. M. 1986, J. Chem. Phys., 85, 1276

Tatum, J. B. 1966, Publications of the Dominion Astrophysical Observatory Victoria, 13, 1

Tennyson, J., \& Yurchenko, S. N. 2012, MNRAS, 425, 21

Ubachs, W., Meyer, G., Ter Meulen, J. J., \& Dymanus, A. 1986, J. Chem. Phys., 84,3032

van Dishoeck, E. F. 1987, J. Chem. Phys., 86, 196

Vázquez, G. J., Amero, J. M., Liebermann, H. P., Buenker, R. J., \& Lefebvre-Brion, H. 2007, J. Chem. Phys., 126, 164302

Watson, J. K. G. 2001, ApJ, 555, 472

Zachwieja, M. 1995, J. Mol. Spectr., 170, 285

Zachwieja, M. 1997, J. Mol. Spectr., 182, 18 